\title{
Forecasting Landslide Generated Tsunamis: a Review
}

\author{
Marcello Di Risio, Paolo De Girolamo and Gian Mario Beltrami \\ University of L'Aquila (DISAT-LIAM) \\ Italy
}

\section{Introduction}

When earthquakes occur, suddenly bottom deformations will induce water response that is almost instantaneous. Then, bottom displacements affect wide areas and generate transient waves (tsunamis) usually characterized by a relatively small height with respect to their length, i.e. by a small steepness. Indeed, just after the earthquake, the water free surface mimics the final bottom deformations, that can be of the order of some meters, and small amplitude long waves start to propagate resulting in a potential transoceanic devastation (Synolakis et al., 2002).

When either subaerial or submerged landslides occur, the displacements will take place on both larger temporal-, and smaller spatial-scale. The deformations are of the order of hundreds of meters and the generated waves are quite different from those induced by submarine earthquakes. Hence, landslide tsunamis tend to be a local phenomenon, although extreme. Since two centuries ago, submarine failures were related to "sea waves without earthquake" when great waves were observed without any account of earthquakes (e.g. Mallet \& Mallet, 1858; Milne, 1898; Montessus de Ballore, 1907). In an illuminating reasoning Mallet \& Mallet (1858) argued that "great underwater slippage takes place [...] the effect upon the surface of the sea is at the same moment to originate a positive and a negative wave. [...] The magnitude of the wave raised is dependent upon that of the mass of solid material that has suddenly changed its place, upon the depth of water in which the slippage has occurred, upon the rapidity of the transposition, and in minor degree upon the form and material of the portion of the bank that has slipped."

One of the more meaningful event occurred at Lituya Bay (Alaska, July 9, 1958), when a subaerial landslide triggered by an earthquake entered the water at the Gilbert Inlet and generated an impulse wave (Miller, 1960). The induced run-up was the highest known: the water rose up to $524 \mathrm{~m}$ at the slope in front of the landslide, then the waves propagated into the Bay and eventually radiated offshore through the Bay inlet with minimum effects outside the Bay itself. Another example, related to submarine failures, is the well documented tsunami generated by an underwater slump triggered by a magnitude 7 earthquake on July 17, 1998 close to the Sissano Lagoon, Sandaun Province, Papua New Guinea (see Synolakis et al., 2002). The tsunami struck about $30 \mathrm{~km}$ wide area, i.e. rather small, by inducing a maximum run-up of about $15 \mathrm{~m}$ and killing over 2100 people.

Landslide generated impulse waves can occur not only at the sea boundaries, but also in enclosed basins (i.e. reservoirs and lakes). The event that took place at the Vajont Valley (Italy) on October 9, 1963 is perhaps the more sorrowful one. A subaerial landslide of about 
270 millions of cubic meters fell into the Vajont reservoir and generated impulse waves that ran up to about $235 \mathrm{~m}$. The waves overtopped the concrete arc dam, flooding the village of Longarone, and causing 1901 casualties (e.g. Panizzo et al., 2005b).

When geological evidence can predict the probable occurrence of landslides, engineering tools are needed in order to forecast the features of the induced free surface perturbation.

At this end, the phenomenon of a landslide tsunami can be qualitatively separated in four different phases, each characterized by its own physical features:

(i) a solid or granular mass starts to move from one of the boundary of a water body;

(ii) an impulsive perturbation is generated as a consequence of the interaction with the water surface;

(iii) the generated perturbation propagates into the water body;

(iv) the propagated perturbation interacts with water body boundaries (i.e. coastlines).

Then, modeling of landslide hazards requires information and data from seismology, geology, geotechnical engineering (i-ii) and hydrodynamics (ii-iii-iv), resulting in a challenging task (Synolakis \& Bernard, 2006).

Figure 1 depicts, although qualitatively, the phenomena. While the first phase (i) is intimately related to geological events, the other phases (ii-iii-iv) encompass challenging hydraulic topics such as the water entry problem, the propagation of the generated water-surface perturbation, as well as the run-up and overtopping at the boundaries.

More in details, when the landslide reaches the free surface (Figure 1, generation area, also referred to as the splash zone in the case of subaerial landslide, Walder et al., 2003), a perturbation is generated and energy exchange between landslide and water takes place. The induced waves quickly leave the generation area and propagate in the near field. The near field features of such a perturbation depend upon the characteristics of the landslide (volume, velocity, underwater travel time, density, porosity, shape of the front, slope angle, etc...). Then the waves propagate in the far field where frequency and directional energy dispersion, refraction and diffraction occur, depending upon water body configuration and waves features. Finally, the perturbation reaches the water body boundaries and it runs up and floods coastal areas, often resulting in great damage and danger for human activities. In the case of reservoirs normal modes (seiches) can be excited and the impulsive perturbation impinges the dam and, for extreme events, overtops or destroys it by flooding downstream. The last two phases (iii-iv) tend to coexist, influencing each other. When the landslide occurs directly at the coast, impulse waves both radiate seaward and propagate alongshore. The complex interaction that exists between the generation and the propagation mechanisms has therefore to be taken into account. In such a case trapped waves can be triggered by the source of the tsunami and propagate along the coast by inducing large wave run-up observed in some real cases (Ursell, 1952; Liu \& Yeh, 1996; Liu et al., 1998; Johnson, 2007).

The present chapter aims at reviewing the available engineering tools that can be used to estimate the features of generated waves and their effects on boundaries, i.e. wave run-up and, in the case of reservoirs, dam overtopping.

The topic is intimately related to experimental investigations carried out in the past aimed at defining empirical formulations. Indeed, when forecasting of impulse waves features and effects is needed in a particular real case, it is possible to (i) build the specific hydraulic model, in which the topography of the area of the probable landslide and of the water body are reproduced (e.g. Davidson \& McCartney, 1975; Chaudhry et al., 1983; Fritz et al., 2001) or (ii) refer to the results of well known basic research experiments performed under idealized 


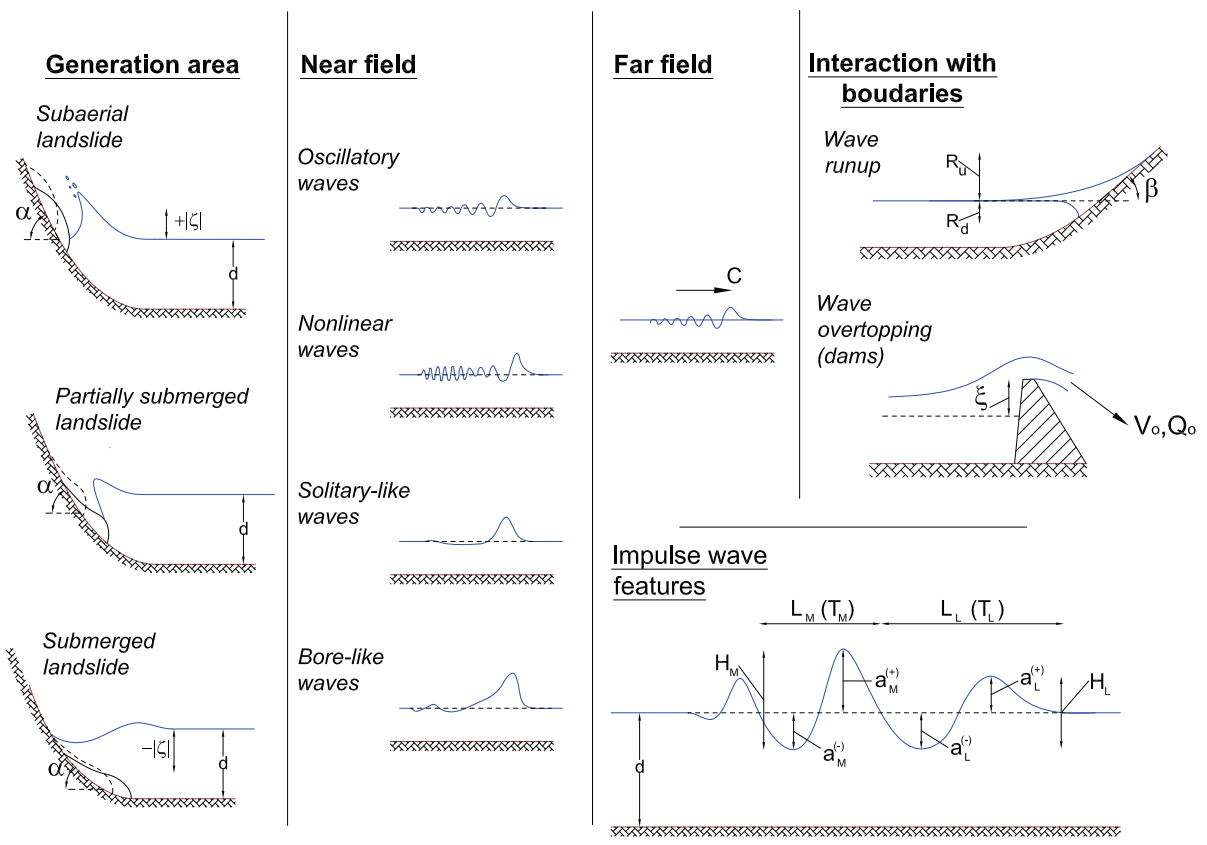

Fig. 1. Qualitative sketch of landslide induced impulse waves.

assumptions, both two-dimensional and three-dimensional, intended to be representative of real cases (e.g. Huber, 1982; Panizzo et al., 2005a; Di Risio et al., 2009a;b).

The chapter is structured as follows. The next section deals with the generation and propagation of impulse waves induced by both underwater and subaerial landslide. The phenomena are qualitatively described and empirical formulations suitable for wave features forecasting are reported on the basis of past researches. The succeeding sections briefly describe the interaction of impulse waves with water body boundaries, i.e. wave run-up and overtopping. Concluding remarks close the chapter. Due to the limited number of pages, only generation and propagation of impulse waves are described in depth.

\section{Impulse waves generation and propagation}

This section deals with experimental investigations aimed at analyzing physical phenomena occurring in the generation area and in the near- and far-field. In the former, landslide energy is transferred to water, whereas in the near- and far-field the waves start to propagate and radiate in the water body.

The first experimental task that has to be addressed is impulse waves reproduction in physical models. The first studies were carried out by Russell $(1838 ; 1845)$. This autor used a vertical falling box in order to generate free surface transient perturbations similar to the "large solitary elevation" (christened "wave of translation") induced by a sudden stop of a boat as observed by Sir Scott Russell along a channel.The box height was higher than the water depth and this impulse waves generation method was used by many authors (e.g. Wiegel et al., 1970; Noda, 1970; Monaghan \& Kos, 2000) and is often referred to as "Scott Russell's wave generator". 
Some authors (e.g. Panizzo et al., 2002; Di Risio, 2005; Di Risio \& Sammarco, 2008; Yim et al., 2008) used a falling box characterized by an height lower than the water depth. In this way, clearly, a return flow occurs over the top of the box and the generator may be addressed as "pseudo-Scott Russells wave generator". Another option to simulate the impulse wave generation by a landslide was to use either a vertical (e.g. Noda, 1970) or an inclined (e.g.Miller, 1970; Iwasaki, 1983; Cea et al., 2004) moving paddle. Several studies have been aimed at providing analytical methods able to define paddle displacements for the generation of cnoidal and solitary waves, similar to impulse waves (e.g. Goring, 1978; Synolakis, 1990; Kattel \& Eric, 2002; Malek-Mohammadi \& Testik, 2010).

However, the preceding methods allow to study the impulse wave propagation, but lack in studying the landslide-water energy exchange. Then, a series of experimental investigations involved the use of solid boxes sliding down inclines (e.g. Wiegel et al., 1970; Heinrich, 1992; Watts, 1998; 2000; Watts et al., 2000; Walder et al., 2003; Panizzo et al., 2005a; Sue et al., 2006; Sue, 2007; Enet \& Grilli, 2007; Ataie-Ashtiani \& Nik-Khah, 2008a;b; Sæ levik et al., 2009) or small calcareous stones (de Carvalho \& do Carmo, 2007). Nevertheless, the shape of the boxes has to be defined preliminarily, and the deformations and porosity of real landslides cannot be reproduced in the model.

Watts et al. (2005) used a validated 2D fully non-linear potential-flow numerical model in order to evaluate the influence of the shape of an underwater solid landslide, and therefore to address the concern about the shape of the solid boxes. These authors found that the higher the spreading of Gaussian shape, the lower the amplitude of generated waves. Then, Watts et al. (2005) indicate that semi-elliptical shaped rigid body represents the worst case scenarios, at least for underwater landslides (Watts, 2000; Enet \& Grilli, 2007; Di Risio et al., 2009a;b). For the case of subaerial landslides, Ataie-Ashtiani \& Nik-Khah (2008a) suggested that the slide shape does not affect substantially the generated waves. However, comprehensive and parametric experimental investigations aimed at evaluating the influence upon the generated waves of the slope of the landslide front $(\gamma)$ have not been carried out so far (at least to our knowledge). The topic was partially tackled by Kamphuis \& Bowering (1970).

In order to reproduce the deformations of the landslide at model scale, some earlier investigations employed sand bags (e.g. Davidson \& McCartney, 1975). Huber (1980; 1982) succesively used granular material with the aim of fully reproducing both deformations and porosity of landslides. More recently, a series of two-dimensional experiments were performed at the Laboratory of Hydraulics, Hydrology and Glaciology of Zurich (VAW-ETH) by using granular landslides with varying geometry and energy (e.g. Fritz et al., 2003a;b; 2004; Zweifel et al., 2006; Heller \& Hager, 2010b). The only three-dimensional experimental investigation with granular landslide is related to an attempt to reproduce the Lituya Bay event (Fritz et al., 2009). However, when granular landslides are used, scale effects will be encountered, mainly related to surface tension and fluid viscosity. This was in particular observed by Heller et al. (2008) when the water depth is lower than $0.20 \mathrm{~m}$. As a general rule, scale effects tend to reduce the generated wave amplitudes, whilst their influence on wave celerity is found relatively small.

For a seek of synthesis, experimental investigations were carried out with solid boxes falling vertically (Scott Russell's wave generator) or sliding along inclines with different shapes (semi-elliptical, triangular, parallelepiped), with deformable sand bags and with granular materials. When comparing solid and granular materials induced waves, for subaerial landslide it seems that there is agreement that solid blocks induce higher waves. In particular, Zweifel (2004) showed that, at least for two-dimensional water bodies, granular landslides 
induce lower waves with respect to that induced by solid blocks. The differences in terms of induced wave amplitude increase as the landslide Froude number $(\mathrm{F})$ increases $\left(=v_{s} / \sqrt{g d}\right.$, being $v_{s}$ the landslide impact velocity and $\sqrt{g d}$ the shallow water wave celerity, $d$ the water depth and $g$ the gravitational acceleration):

$$
\frac{a_{M b} / d-a_{M} / d}{a_{M b} / d}=1-0.26 \mathrm{~F}
$$

where $a_{M}$ is the maximum wave amplitude for granular landslide and $a_{M B}$ for solid blocks (for wave parameters symbols see Figure 1). As discussed by Heller \& Kinnear (2010a), the differences arise from the influence of porosity (being zero for solid blocks), slide front angle (being fixed for solid blocks and time varying for granular landslides), transition between slope toe and channel bottom. Furthermore the blockage ratio $\left(=w / w_{f}\right)$ can influence induced waves. Indeed, for two-dimensional experiments with granular material, the landslide model fill the whole channel width $\left(w_{f}\right)$, whereas solid blocks width $(w)$ has to be lower than channel one in order to allow it to slide the incline.

On the other hand, in the case of underwater landslides, the differences between granular landslides and solid blocks are controversial. Some numerical simulations suggested that intense slide deformation in shallow water, even if crudely represented, induce higher waves (Grilli \& Watts, 2005). Some experiments were conducted with deformable underwater landslide (Fleming et al., 2005; Ataie-Ashtiani \& Nik-Khah, 2008b). It was observed that both sand bags and granular underwater landslide induce lower waves if compared with solid blocks ones (Ataie-Ashtiani \& Nik-Khah, 2008b). In the authors' opinion this aspect should be investigated. Furthermore, differences can arise from the transition between slope toe and channel bottom. It was observed that a sudden stop of solid underwater blocks induce higher waves if compared with a smooth transition allowing the landslide model to decelerate naturally at the horizontal bottom (Sue et al., 2006; Koo \& Kim, 2008).

In the following subsections, forecasting formulae for subaerial and underwater landslide induced waves are reviewed.

\subsection{Subaerial landslides generated waves}

A qualitative description of the phenomena can be found in Liu et al. (2005) and Di Risio et al. (2009a). When landslide enters the water body, it pushes ahead the fluid and a leading positive seaward radiating wave is generated. Once the landslide becomes totally submerged, the water is initially depressed by generating a trailing wave through. Strong alongshore free surface gradients occur in the generation area resulting in converging flows that collide and rebound along the centreline of the landslide. The rebound is the responsible of a large positive wave radiating offshore. This section deals with the problem of forecasting the features of the generated and offshore-radiated waves.

Earlier experiments were conducted in two-dimensional wave flumes facing the problem of impulse wave propagation arising from water surface disturbances ((Prins, 1958), i.e. related to the classical problem of Cauchy-Poisson, Lamb, 1932, +238 - 240). In that study the leading wave types were inferred from experimental observations, i.e. oscillatory linear waves, solitary-like and cnoidal waves as well as bore-like waves (see Figure 1), depending on the geometrical features of wave disturbance, i.e. its height and length. However, the surface disturbances were static, then Miller (1970) extended the work by Prins (1958) by using a moving vertical paddle with the aim of gaining insight about the relationship between leading wave type and paddle Froude number. Then Wiegel et al. (1970) used the 
Scott Russell's wave generator and Noda (1970) related the wave type to landslide Froude number, i.e. the ratio between the falling box velocity $\left(v_{s}\right)$ and shallow water waves celerity $(\sqrt{g d})$. Furthermore, for the case of horizontal moving paddle, he provided an empirical formulation for maximum wave crest amplitude based on his linear analytical modeling (Table 1, abbreviation NODA1970). In the meantime, Kamphuis \& Bowering (1970) provided the first empirical formulations based on their own experiments (Bowering, 1970). The experiments consisted in a tray sliding down an incline. They proposed a dimensional analysis, by defining the relationships $f$ between any dependent quantity (in dimensionless form, $\Pi$ ):

$$
\Pi=f\left(\mathrm{~F}, \mathrm{M}, \mathrm{G}, \mathrm{X}, \mathrm{S}, t \sqrt{\frac{g}{d}}, \gamma, \alpha, p\right)
$$

where $\mathrm{F}$ is the already defined landslide Froude number $\left(=v_{s} / \sqrt{g d}\right), \mathrm{M}$ is the dimensionless two-dimensional landslide volume $\left(=V_{s} / w d^{2}, V_{s}\right.$ the landslide volume, $w$ landslide width, $d$ water depth), $\mathrm{G}$ the specific gravity $\left(=\rho_{s} / \rho, \rho_{s}\right.$ the landslide bulk density, $\rho$ water density), $X$ the dimensionless propagation distance $(=x / d, x$ the distance from impact point), $t$ the time, $g$ the gravitational acceleration, $\gamma$ the landslide front slope, $\alpha$ the slope angle of the incline to horizontal, $p$ the landslide porosity. Experimental investigation showed that the generated maximum wave height $H_{M}$ is strongly affected by the dimensionless volume (M) and landslide Froude number $(\mathrm{F})$. The leading wave period $T_{l}$ is affected only by the dimensionless distance. Empirical formulations are reported in Tables 1 and 2 (abbreviation KB1970).

The first three-dimensional experimental investigation was carried out by Huber $(1980 ; 1982)$. He performed several two-dimensional experiments by employing a granular landslide model. Then the experimental results were compared with a limited number of three-dimensional experimental findings in order to estimate a reduction parameter capable of taking into account the three-dimensional effects due to lateral dispersion. Empirical correlations were provided only on a tabular form, but Huber \& Hager (1997) re-analyzed the same experimental data and a series of empirical formulation were defined, for both two- and three-dimensional water bodies (HH1997 in Table 1). They found that, for two-dimensional water body, the main effect on wave height is related to the slope angle $(\alpha)$ : the lower the slope angle, the lower the wave height. Furthermore, increasing dimensionless landslide volume (M) and specific gravity $(G)$ and decreasing of dimensionless distance $(X)$ result in increasing wave height. Nevertheless, they simulated fast landslides, then the influence of landslide Froude number was not addressed. Three-dimensional water bodies lateral dispersion are modeled by a squared cosine function involving the wave propagation direction $\theta$ (measured with respect to the direction of landslide motion). After few years, granular material was used to simulate landslides within a long series of two-dimensional experiments at the wave flume of VAW-ETH (Zurich). The experimental observations were used to characterize the water flow in the near- and far-field (Fritz et al., 2003a), as well as the impact crater features (Fritz et al., 2003b), scale effects influence on experimental results (Heller et al., 2008), wave types (Fritz et al., 2004). Also, a series of empirical formulations were defined (Fritz et al., 2004; Zweifel et al., 2006; Heller \& Kinnear, 2010a). By means of large scale PIV measurements they found that fluid velocities exist always after the landslide impact, then when dealing with numerical simulations, free surface does not suffice and also velocity fields have to be considered. They observed that the flow is substantially irrotational except close to the interface between granular material and water and in the rear of the landslide where turbulent flow occurs. These observations confirm the assumptions made in using of mathematical method, either numerical or analytical, based on Laplace equation. Of particular interest for 
our purposes is the empirical formulations proposed by this research group. Indeed, different empirical formulations were provided with different experimental ranges and by considering several dimensionless groups (ETH2004, ETH2006 and ETH2010 in Tables 1 and 2). The influences of (i) landslide Froude number (F), (ii) dimensionless landslide thickness $(\mathrm{S}=s / w$, being the landslide thickness $s$ measured perpendicular to the incline), (iii) specific gravity (G) and (iv) incline slope $(\alpha)$ are addressed: the higher the values of M, S, G, the higher the induced wave height and period; the lower the value of $\alpha$ (i.e. less steep inclines), the higher the induced wave height and period. It has to be stressed that the influence of the incline slope seems to be in contrast with the three-dimensional results showed by Huber \& Hager (1997) that observed increasing wave height for increasing $\alpha$.

Other experimental investigations were carried out by using solid landslides. Walder et al. (2003), on the basis of an interesting scaling analysis of the Euler equations, demonstrated the importance of the dimensionless underwater travel time $\tau\left(=t_{s} / \sqrt{g d}\right.$, being $t_{s}$ the underwater travel time), as confirmed analytically by Di Risio \& Sammarco (2008), the dimensionless landslide volume $\mathrm{M}$, the landslide Froude number $\mathrm{F}$ and of the incline slope $\alpha$. They proposed empirical formulations for maximum wave height in the near field involving the dimensionless underwater travel time and landslide volume (W2003 in Table 1). It was shown that such a relationships can model also the experimental data collected during past researches (Bowering, 1970; Huber, 1980). In this way, knowledge of underwater travel time is needed, and they related it to dimensionless landslide length $\tilde{\mathrm{L}}(=L / d$, being $L$ the landslide length measured along the incline). However the authors report in the paper the values of empirical coefficients based on their own data only. Furthermore they related the near field wavelength to underwater landslide, needed to estimate the extension of the near field, i.e. about three times the wavelength. It has to be stressed that the estimation of underwater travel time, and in turn wavelength and near field extension, did not involve the slope angle $\alpha$. Synthetically, the experimental work of Walder et al. (2003) showed that wave height increases for decreasing underwater travel time (then decreasing dimensionless landslide length) and increasing dimensionless landslide volume. It has to be stressed that the blockage ratio for those experiments was quite less than unity (i.e. equal to 0.53), therefore experimental data could be somewhat affected by some reduction (Heller \& Kinnear, 2010a).

Further two-dimensional tests aimed at providing empirical formulations were performed by Di Risio (2005). He performed a series of experimental tests in the Environmental and Maritime Hydraulics Laboratory (LIAM) of the University of L'Aquila, by using a pseudo-Scott Russell's wave generator (i.e. being the height of the box lower than water depth) in a two-dimensional wave flume. He provided empirical formulations (LIAM2005-2D in Table 1), based on the dimensional analysis by Kamphuis \& Bowering (1970), equation (2), by keeping constant the porosity $(p=0)$, the slope angle $\left(\alpha=90^{\circ}\right)$, the landslide front slope $\left(\gamma=90^{\circ}\right)$ and the specific gravity $(G=1.36)$. This study represent an extension of the work by Kamphuis \& Bowering (1970), even if only for vertical landslides. Moreover he performed a series of axial symmetric experiments by using a vertical falling solid body (a kind of cylindrical Scott Russell's wave generator) and by providing further empirical formulations (LIAM2005-AX in Tables 1 and 2). Similar behavior of wave features were found for both two-dimensional and axial symmetric water bodies: the higher the landslide Froude number $(\mathrm{F})$ and the dimensionless landslide thickness (S) and the shorter the dimensionless distance ( $\mathrm{X}$ or $\mathrm{R}=r / d$, being $r$ the distance from impact point in three-dimensional water body), the higher the maximum and leading wave height and crest amplitude. For the wave period it was found that it is slightly affected by the landslide Froude number. 


\begin{tabular}{|c|c|c|c|}
\hline $\begin{array}{c}\text { Ref. } \\
\text { (Abbr.) }\end{array}$ & $\mathrm{H}_{\mathrm{M}} / \mathrm{d}$ & $\mathrm{a}_{\mathrm{M}} / \mathrm{d}$ & $\mathrm{T}_{\mathrm{M}} \sqrt{\mathrm{g} / \mathrm{d}}$ \\
\hline $\begin{array}{l}\text { Noda }(1970) \\
\text { (NODA1970) }\end{array}$ & $=$ & $1.32 \mathrm{~F}$ & $=$ \\
\hline $\begin{array}{l}\text { Kamphuis \& Bowering (1970) } \\
\text { (KB1970) }\end{array}$ & $\begin{array}{r}\mathrm{F}^{0.7}(0.31+0.20 \log \mathrm{M})+ \\
\quad+0.35 \exp (-0.08 \mathrm{X})\end{array}$ & $=$ & $=$ \\
\hline $\begin{array}{l}\text { Huber \& Hager (1997) } \\
\quad(\text { HH1997-2D) }\end{array}$ & $0.88 \mathrm{G}^{0.25} \mathrm{M}^{0.5} \mathrm{X}^{-0.25} \sin \alpha$ & $=$ & $=$ \\
\hline $\begin{array}{l}\text { Huber \& Hager (1997) } \\
\text { (HH1997-3D) }\end{array}$ & $1.76 \mathrm{G}^{0.25} \mathrm{M}^{0.5} \mathrm{R}^{-0.67} \sin \alpha \cos ^{2}(0.67 \theta)$ & $=$ & $=$ \\
\hline $\begin{array}{l}\text { Walder et al. (2003) } \\
\qquad \text { (W2003) }\end{array}$ & $=$ & $\begin{array}{l}1.32(\tau / \mathrm{M})^{-0.68} \\
\quad \text { with } \quad \tau=4.5 \tilde{\mathrm{L}}^{0.5}\end{array}$ & $=$ \\
\hline $\begin{array}{l}\text { Fritz et al. (2004) } \\
\text { (ETH2004) }\end{array}$ & $=$ & $0.25 \mathrm{~F}^{1.4} \mathrm{~S}^{0.8}$ & $=$ \\
\hline $\begin{array}{l}\text { Panizzo et al. (2005) } \\
\text { (LIAM2005-3D) }\end{array}$ & $\begin{array}{l}0.102 \Sigma^{0.572} \mathrm{~F}^{0.297} \mathrm{R}^{-0.440}(\sin \alpha)^{-0.286} \\
\quad \cdot \exp (0.6 \cos \theta)\end{array}$ & $=$ & $3.010 \Sigma^{0.279} \mathrm{~F}^{0.145} \mathrm{R}^{0.17}(\sin \alpha)^{-0.04}$ \\
\hline $\begin{array}{l}\text { Di Risio (2005) } \\
\text { (LIAM2005-2D) }\end{array}$ & $0.897 \mathrm{~S}^{0.642} \mathrm{~F}^{0.531} \mathrm{X}^{-0.273}$ & $0.572 \mathrm{~S}^{0.832} \mathrm{~F}^{0.398} \mathrm{X}^{-0.215}$ & $5.638 \mathrm{~S}^{0.078} \mathrm{~F}^{0.053} \mathrm{X}^{0.374}$ \\
\hline $\begin{array}{l}\text { Di Risio (2005) } \\
\text { (LIAM2005-AX) }\end{array}$ & $0.264 \mathrm{~S}^{1.535} \mathrm{~F}^{0.527} \mathrm{R}^{-0.828}$ & $=$ & $11.2 \mathrm{~S}^{0.847} \mathrm{R}^{0.110}$ \\
\hline $\begin{array}{l}\text { Zweifel et al. (2006) } \\
\quad(\text { ETH2006) }\end{array}$ & $=$ & $\begin{array}{l}\text { Near field: } \\
\quad 0.33 \mathrm{FS}^{0.5} \mathrm{M}^{0.25} \mathrm{G}^{0.25} \\
\text { Far field: } \\
\quad 2 \mathrm{~S}^{0.5} \tanh \left(0.25 \mathrm{~F}^{1.5} \mathrm{M}^{0.5} \mathrm{G}^{0.5} \mathrm{X}^{-0.5}\right)\end{array}$ & $=$ \\
\hline $\begin{array}{c}\text { Ataie-Ashtiani \& Nik-Khah (2008) } \\
\text { (AANK2008) }\end{array}$ & $=$ & $\begin{array}{l}\left(0.398+0.076 \mathrm{M}^{1.27} \mathrm{~F}^{2.54}\right) \tau^{-0.26} \\
\cdot \mathrm{M}^{0.26} \tilde{\mathrm{L}}^{-0.125} \mathrm{~S}^{0.125} \mathrm{X}^{-0.48}\end{array}$ & $\begin{array}{l}\left(4.14+3.88 \mathrm{M}^{2} \mathrm{~F}^{4}\right) \tau^{-0.114} \\
\cdot \mathrm{M}^{0.114} \tilde{\mathrm{L}}^{0.1} \mathrm{~S}^{-0.1} \mathrm{X}^{0.16}\end{array}$ \\
\hline $\begin{array}{l}\text { Heller \& Hager (2010) } \\
\text { (ETH2010) }\end{array}$ & $\begin{array}{l}\text { Near field: } \\
0.56 \mathrm{~F}^{0.8} \mathrm{M}^{0.2} \mathrm{G}^{0.2} \mathrm{~S}^{0.4}(\cos 0.9 \alpha)^{0.4} \\
\text { Far field: } \\
0.75 \mathrm{~F}^{0.8} \mathrm{M}^{0.2} \mathrm{G}^{0.2} \mathrm{~S}^{0.4}(\cos 0.9 \alpha)^{0.4} \mathrm{X}^{-0.27}\end{array}$ & $\begin{array}{l}\text { Near field: } \\
0.44 \mathrm{~F}^{0.8} \mathrm{M}^{0.2} \mathrm{G}^{0.2} \mathrm{~S}^{0.4}(\cos 0.9 \alpha)^{0.4} \\
\text { Far field: } \\
0.60 \mathrm{~F}^{0.8} \mathrm{M}^{0.2} \mathrm{G}^{0.2} \mathrm{~S}^{0.4}(\cos 0.9 \alpha)^{0.4} \mathrm{X}^{-0.27}\end{array}$ & $\begin{array}{l}\text { Near field: } \\
9 \mathrm{~F}^{0.5} \mathrm{M}^{0.13} \mathrm{G}^{0.13} \mathrm{~S}^{0.25}(\cos 0.9 \alpha)^{0.25} \\
\text { Far field: } \\
9 \mathrm{~F}^{0.25} \mathrm{M}^{0.06} \mathrm{G}^{0.06} \mathrm{~S}^{0.13}(\cos 0.9 \alpha)^{0.13} \mathrm{X}^{0.31}\end{array}$ \\
\hline
\end{tabular}

Table 1. Empirical formulations for subaerial landslide generated waves. Highest wave.

\begin{tabular}{|c|c|c|c|}
\hline $\begin{array}{c}\text { Ref. } \\
\text { (Abbr.) }\end{array}$ & $\mathrm{H}_{1} / \mathrm{d}$ & $\mathrm{a}_{\mathrm{l}} / \mathrm{d}$ & $\mathrm{T}_{1} \sqrt{\mathrm{g} / \mathrm{d}}$ \\
\hline $\begin{array}{c}\text { Kamphuis \& Bowering (1970) } \\
\text { (KB1970) }\end{array}$ & $=$ & $=$ & $11+0.225 \mathrm{X}$ \\
\hline $\begin{array}{l}\text { Fritz et al. (2004) } \\
\quad(\text { ETH2004) }\end{array}$ & $=$ & $=$ & $4.92 \mathrm{~F}^{0.5} \mathrm{M}^{0.2} \mathrm{X}^{0.33}(c / \sqrt{g d})^{-1}$ \\
\hline $\begin{array}{l}\text { Panizzo et al. (2005) } \\
\text { (LIAM2005-3D) }\end{array}$ & $\begin{array}{l}0.090 \Sigma^{0.381} \mathrm{~F}^{0.198} \mathrm{R}^{-0.810}(\sin \alpha)^{-0.404} \\
\quad \cdot \exp (1.37 \cos \theta)\end{array}$ & $\begin{array}{l}0.025 \Sigma^{0.343} \mathrm{~F}^{0.178} \mathrm{R}^{-0.800}(\sin \alpha)^{-0.544} \\
\quad \cdot \exp (1.60 \cos \theta)\end{array}$ & $6.960 \mathrm{R}^{0.18} \exp (0.23 \cos \theta)$ \\
\hline $\begin{array}{l}\text { Di Risio (2005) } \\
\text { (LIAM2005-AX) }\end{array}$ & $0.268 \mathrm{~S}^{1.711} \mathrm{~F}^{0.553} \mathrm{R}^{-0.934}$ & $=$ & $9.43 \mathrm{~S}^{0.508} \mathrm{~F}^{0.112} \mathrm{R}^{0.177}$ \\
\hline
\end{tabular}

Table 2. Empirical formulations for subaerial landslide generated waves. Leading wave. 


\begin{tabular}{|c|c|c|c|c|c|c|c|c|c|c|}
\hline $\begin{array}{c}\text { Ref. } \\
\text { (Abbr.) }\end{array}$ & $\begin{array}{c}\text { Landslide } \\
\text { model }\end{array}$ & F & $M$ & $G$ & $\Sigma$ & $X,(R)$ & S & $\alpha\left(^{\circ}\right)$ & $\theta\left(^{\circ}\right)$ & $\gamma\left(\left(^{\circ}\right)\right.$ \\
\hline $\begin{array}{l}\text { Kamphuis \& Bowering (1970) } \\
\text { (KB1970) }\end{array}$ & Solid & $0.9-3.1$ & $0.04-0.79$ & 2.7 & $=$ & $7.2-74.3$ & $=$ & $20-90$ & $=$ & $75.5-101.5$ \\
\hline $\begin{array}{l}\text { Huber \& Hager (1997) } \\
\quad(\text { HH1997-2D) }\end{array}$ & Granular & $0.53-3.69$ & $0.03-2.60$ & 1.33 & $=$ & $5-100$ & $=$ & $28-50$ & $=$ & $=$ \\
\hline $\begin{array}{l}\text { Huber \& Hager (1997) } \\
\quad(\text { HH1997-3D) }\end{array}$ & Granular & $0.53-3.69$ & $0.03-2.60$ & 1.33 & $=$ & $5-30$ & $=$ & $28-50$ & $0-90$ & $=$ \\
\hline $\begin{array}{l}\text { Walder et al. (2003) } \\
\qquad(\text { W2003) }\end{array}$ & Solid & $1.0-4.1$ & $0.14-3.24$ & 2.9 & $0.28-2.94$ & $8-20$ & $0.24-1$ & $11.2-19.5$ & $=$ & 32 \\
\hline $\begin{array}{l}\text { Fritz et al. (2004) } \\
\quad \text { (ETH2004) }\end{array}$ & Granular & $1.08-4.66$ & $0.07-6.19$ & 1.62 & $=$ & $0-25$ & $0.07-0.60$ & 45 & $=$ & $=$ \\
\hline $\begin{array}{l}\text { Panizzo et al. (2005) } \\
\text { (LIAM2005-3D) }\end{array}$ & Solid & $1.0-2.2$ & $=$ & 2.2 & $0.04-0.68$ & $1.3-15.1$ & $0.11-0.45$ & $16-36$ & $0-90$ & 90 \\
\hline $\begin{array}{l}\text { Di Risio (2005) } \\
\text { (LIAM2005-2D) }\end{array}$ & Solid & $0.29-2.58$ & $0.09-4.17$ & 1.36 & $0.28-12.50$ & $1.7-89.2$ & $0.22-2.50$ & 90 & $=$ & 90 \\
\hline $\begin{array}{l}\text { Di Risio (2005) } \\
\text { (LIAM2005-AX) }\end{array}$ & Solid & $0.29-2.64$ & $0.03-0.90$ & 1.36 & $0.30-8.96$ & $1.7-52.6$ & $0.87-4.78$ & 90 & $=$ & 90 \\
\hline $\begin{array}{l}\text { Zweifel et al. (2006) } \\
\quad(\text { ETH2006) }\end{array}$ & Granular & $1.08-4.89$ & $0.04-1.36$ & $0.95-2.64$ & $=$ & $0-49$ & $0.08-1.13$ & 45 & $=$ & $=$ \\
\hline $\begin{array}{c}\text { Ataie-Ashtiani \& Nik-Khah (2008) } \\
\text { (AANK2008) }\end{array}$ & Solid & Not Declared & $9-240$ & 1.9 & $0.02-0.18$ & $0-7.2$ & $0.1-0.4$ & $15-60$ & $=$ & $60-90$ \\
\hline $\begin{array}{l}\text { Heller \& Hager (2010) } \\
\quad \text { (ETH2010) }\end{array}$ & Granular & $0.86-6.83$ & $0.05-2.98$ & $0.59-1.72$ & $=$ & $0-59$ & $0.09-1.64$ & $30-90$ & $=$ & $=$ \\
\hline
\end{tabular}

Table 3. Experimental ranges for empirical formulations of Tables 1-2.

Similar qualitative behavior was observed by Panizzo et al. (2005a) in the case of three-dimensional water bodies (LIAM2005-3D in Tables 1 and 2). They used a tray sliding along an incline that generated impulse waves in a wave tank. The slope of the incline was adjustable, so they investigated also the influence of $\alpha$ on generated waves. Actually, they followed the scaling analysis proposed by Walder et al. (2003), but their results showed that the underwater travel time depends on the same dimensionless groups proposed by Kamphuis \& Bowering (1970). They found that the generated wave height increases as the landslide Froude number $(\mathrm{F})$ and the dimensionless landslide front area $\left(\Sigma=w s / d^{2}\right)$ increase. Furthermore they observed that the wave height grows as the incline slope $(\alpha)$ becomes smaller, therefore in contrast with the formulation by Huber \& Hager (1997).

Ataie-Ashtiani \& Nik-Khah (2008a) showed that the landslide shape does not strongly affect the wave height. They proposed their own empirical formulations (AANK2008 in Table 1) that work well also for experimental data by Bowering (1970), Huber \& Hager (1997) and Walder et al. (2003). It has to be noted that the data collected by Huber \& Hager (1997) is related to granular landslide models that should result in lower wave height if compared with experiments performed with solid blocks (Zweifel, 2004; Heller \& Kinnear, 2010a). The doubt can be partially solved by observing that the experiments performed by Walder et al. (2003) and Ataie-Ashtiani \& Nik-Khah (2008a) are characterized by a blockage ratio $\left(=w / w_{f}\right.$, being $w_{f}$ the wave flume width) equal to 0.526 and about 0.12 respectively. Indeed, as indicated by Heller \& Kinnear (2010a), decreasing blockage ratio tends to reduce generated wave height. 
Inspection of empirical formulations (see Tables 1 and 2) reveals that wave height (or wave crest amplitude) increases as dimensionless Froude number (F), dimensionless landslide volume (M) or dimensionless landslide front area $(\Sigma)$, dimensionless landslide thickness (S) and specific gravity $(\mathrm{G})$ increase. As far as the slope of the incline $(\alpha)$ is concerned, all the formulations but the one by Huber \& Hager (1997) indicated that the lower the slope, the higher the wave height. Wave height attenuation is larger in three-dimensional and axial symmetric water bodies with respect to two-dimensional geometries. The landslide front slope angle $(\gamma)$ influence was investigated only by Kamphuis \& Bowering (1970) and Heller \& Hager (2010b). When the angle that the front of landslides forms with water $(=\pi-\alpha-\gamma)$ decreases, wave height will increases too. In general, granular landslides seems to generate lower waves as indicated by Zweifel (2004) and landslide shape does not affect significantly the induced wave height (Ataie-Ashtiani \& Nik-Khah, 2008a).

The induced wave period is strongly related only to dimensionless distance from generation area $(X$ or $R)$ : the higher the distance, the higher the wave period, i.e. wave dispersion occurs. The influences of landslide Froude number $(\mathrm{F})$, the slope of the incline $(\alpha)$, the specific gravity $(\mathrm{G})$ and the dimensionless landslide volume (M) seems to be slight.

It has to be noticed that for the use of some empirical formulations (i.e. W2003 and AAKK2008) the dimensionless underwater travel time value $(\tau)$ is needed. The only available formulations are those proposed by Walder et al. (2003) and Panizzo et al. (2005a):

$$
\tau=4.5 \sqrt{\tilde{\mathrm{L}}} \quad ; \quad \tau=0.43 \Sigma^{-0.27} \mathrm{~F}^{-0.66}(\sin \alpha)^{-1.32}
$$

As observed by Walder et al. (2003), the first of equations (3), should be used when landslide motion is manly affected by frictional forces (i.e. Coulumbic friction) and hydrodynamic drag is less important (Savage \& Hutter, 1989).
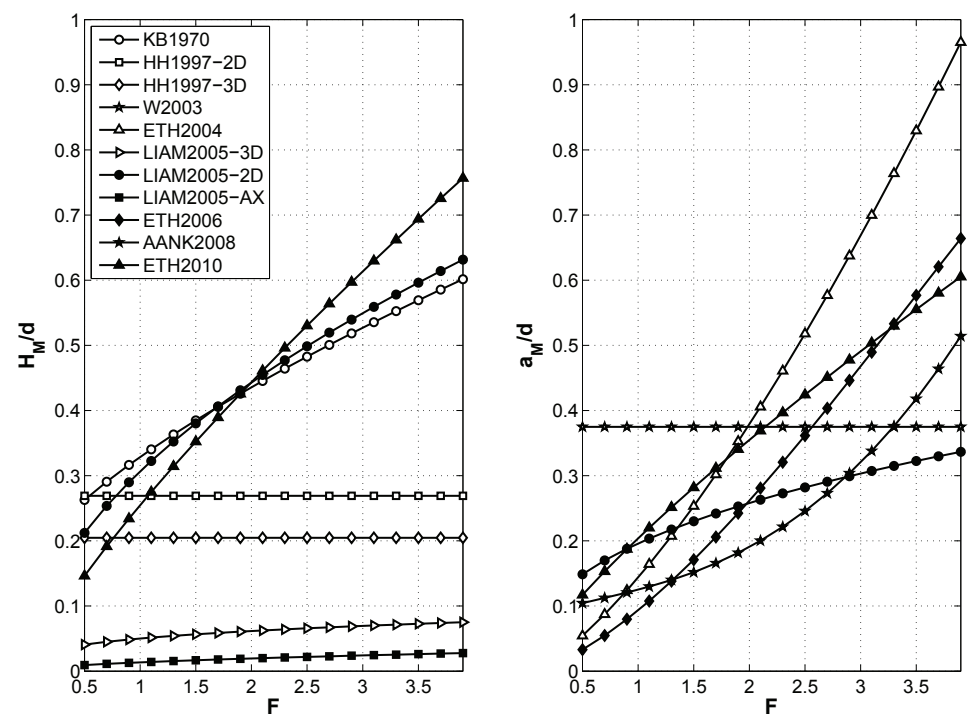

Fig. 2. Computed values of relative maximum wave height $\left(H_{M} / d\right)$ and maximum wave crest amplitude $\left(a_{M} / d\right)$ for varying landslide Froude number $\mathrm{F}(\mathrm{M}=0.5, \mathrm{G}=1.4, \Sigma=0.5$, $\mathrm{X}=R=5, \mathrm{~S}=0.5, \alpha=45^{\circ}, \theta=0^{\circ}$ ) 
Figure 2 compares the computed maximum wave height (left panel) and maximum wave crest amplitude (right panel) with the empirical formulations described above (Tables 1). It has to be noted that HH1997-3D and LIAM2005-3D are based on three-dimensional experiments, LIAM2005-AX on axial symmetric water bodies, whereas the others refer to two-dimensional investigations. In order to compare the formulations, the curves are plotted together by keeping fixed some parameters $\left(\mathrm{M}=0.5, \mathrm{G}=1.4, \Sigma=0.5, \mathrm{X}=R=5, \mathrm{~S}=0.5, \alpha=45^{\circ}, \theta=0^{\circ}\right)$. It has to be stressed that some formulations are applied outside their own experimental ranges (see Table 3). Some considerations arise from figure inspection. Maximum wave height is considered first. As expected, the lowest wave height is estimated by LIAM2005-AX and LIAM2005-3D. The three-dimensional results are higher than the axial symmetric ones, due to (i) the wave directivity that is present for the experiments of Panizzo et al. (2005a) and totally absent in axial symmetric geometries (Di Risio, 2005) and (ii) as axial symmetric experiments were carried out with vertical falling solid boxes $\left(\alpha=90^{\circ}\right)$. For landslide Froude number lower than about 2.0, empirical formulation ETH2010, based on granular material experiments, gives lower maximum wave height than LIAM2005-2D and KB1970, based on solid blocks experiments. However the differences decrease with increasing landslide Froude number, somewhat in contrast with Zweifel (2004). Furthermore, for landslide Froude number higher than about 2.0, granular material experiments give higher maximum wave height than solid blocks ones. The higher the value of dimensionless landslide thickness (S), the higher the landslide Froude number from which granular landslide models give higher wave height. However it has to be noted that landslide Froude number experimental ranges of LIAM2005-2D and KB1970 are 2.6 and 3.1 respectively.

As far as the maximum wave crest amplitude is concerned (Figure 2, right panel), it can be noted that the ETH's empirical formulations give the higher values for high landslide Froude numbers, i.e. granular material seems to induce higher crest elevation. For landslide Froude number lower than about 2.0, the empirical formulation proposed by Walder et al. (2003) on the basis of solid blocks experiments gives the highest value. For higher values of F, ETH2004-2006-2010, based on granular landslide experiments, give higher values than the solid boxes. It could be argued that the deformability of granular slide plays a role in generating waves for high landslide Froude number due to increasing of landslide front area that, as indicated by Panizzo et al. (2005a), induces an increasing of wave height. This aspect should be addressed in order to clarify the applicability of empirical formulations.

\subsection{Underwater landslides generated waves}

Physical features of underwater landslide generated waves are significantly different from that induced by subaerial landslides described in the previous section. As observed experimentally by Enet \& Grilli (2007) in a three-dimensional wave tank, when underwater landslides occur, a depression of free surface takes place above the initial location of the slide. Then it rebounds to generate elevation perturbation radiating offshore as a leading elevation $\mathrm{N}$-wave (Tadepalli \& Synolakis, 1994) followed by trailing smaller waves. The rebound wave also propagates shoreward and is reflected by the shore, inducing wave run-up.

One of the first experimental works was carried out by Wiegel (1955) who used solid boxes, either falling vertically or sliding down an incline, in order to generate impulse waves in a two-dimensional wave flume. It was observed that the wave amplitude increases as the submerged weight increases and the initial submergence of the slide $(|\zeta|)$ decreases. The wave period is related to the length of the slide and on the slope of the incline: the flatter the incline (the lower the slope $\alpha$ ), the greater the wave period. 
As the landslide starts to move when it is totally submerged, the features of generated waves are likely to be strongly related to the landslide motion. This aspect was addressed by the key work of Watts (1998). His experimental work was devoted at providing a method aimed at defining empirical formulation giving characteristic wave amplitude at a particular distance away from initial location of a submerged landslide. Based on scaling analysis of Euler equations, similar to Walder et al. (2003), he provided the following dimensional relationship:

$$
\frac{\eta}{x_{0}}=f\left(\frac{b}{|\zeta|}, \alpha, \mathrm{Z}, \mathrm{HA}_{0}\right)
$$

where $\eta$ is the characteristic wave amplitude, $b$ is the horizontal dimensions of the landslide, $|\zeta|$ the initial submergence, $\alpha$ the slope of the incline, already used for subaerial landslide, $Z$ the submergence number $\left(=x_{0} \sin \alpha /|\zeta|\right)$, related to the characteristic length of landslide motion $\left(x_{0}\right)$, and $\mathrm{HA}_{0}$, the Hammack number $\left(=t_{0} \sqrt{g d} / b\right)$, is related to the characteristic time of the landslide motion $\left(t_{0}\right)$. It has to be noted that, compared to the subaerial landslide generated waves problem, the landslide Froude number does not suffice to describe the phenomena. In particular, some measurements of the characteristic of the landslide motion are needed (i.e. $x_{0}$ and $t_{0}$ ). Based on theoretical analysis of solid block motion proposed by Pelinovsky \& Poplavsky (1996), it was showed that characteristic length $x_{0}$ and time $t_{0}$ of landslide motion can be related to the initial acceleration $a_{0}$ and terminal velocity $u_{t}$ :

$$
x_{0}=u_{t}^{2} / a_{0} \quad ; \quad t_{0}=u_{t} / a_{0}
$$

that, in turn, are related to the dynamical forces acting on the landslide during its motion (i.e. Coulumbic friction force, added mass force and hydrodynamic drag). Then the influence of initial acceleration and terminal velocity upon the induced wave is emphasized. Furthermore, the Hammack number represents a dimensionless near field wavelength (Watts, 2000). Indeed, characteristic wavelength $\lambda_{0}$ can be expressed in terms of the characteristic time of landslide motion $\left(=t_{0} \sqrt{g d}\right)$, and the Hammack number is the ratio between $\lambda_{0}$ and the horizontal landslide length $b$. This result is similar to the analytical one by Tuck \& Hwang (1972) who showed that waves dispersion can be neglected (i.e. the near field) up to a distance of $b /(\tan \alpha)^{2}$ when an underwater disturbance of scale length $b$ occurring on a sloping beach that forms an angle $\alpha$ to the horizontal generates an impulse waves train. Hence, the key result of the work by Watts (1998) is the formal coupling of the landslide motion to the generated waves (non-dimensional wave curve). Based on this formalism, Grilli \& Watts (2005) and Watts et al. (2005) performed a series of two-dimensional numerical simulations aimed at providing empirical formulations giving the wave amplitude in the near field. The shape of the underwater landslide was selected on the basis of some preliminary simulations (Grilli \& Watts, 2005) that indicated the semi-elliptical landslides as the worst case scenarios. The empirical formulation reads as follows (hereinafter referred to as W2005-2D, Watts et al., 2005):

$$
\eta_{2 D}=\frac{u_{t}^{2}}{a_{0}}(0.0574-0.0431 \sin \alpha) S_{b}\left(\frac{L \sin \alpha}{|\zeta|}\right)^{1.25}\{1-\exp [-2.2(\mathrm{D}-1)]\}
$$

where $S_{b}$ is a different definition of dimensionless landslide thickness $(=s / b)$ if compared to that used for subaerial landslide. Formulation (6) is valid within the following ranges: $5^{\circ}<\alpha<30^{\circ}, 0.06<b / d<1.5,0.008<\mathrm{S}_{b}<0.2,1.46<\mathrm{D}<2.93$. In order to provide also three-dimensional wave amplitude, the following relationship was proposed by the same 
authors (hereinafter referred to as W2005-3D):

$$
\eta_{3 D}=\eta_{2 D}\left(\frac{w}{w+\lambda_{0}}\right)
$$

where $w$ is the landslide width and $\lambda_{0}$ is the characteristic wavelength $\left(=t_{0} \sqrt{g d}\right)$.

The three-dimensional experimental work by Enet \& Grilli (2007) confirmed the importance of initial acceleration and terminal velocity and successfully validated the empirical formulation provided by Watts et al. (2005).

Based on three-dimensional experiments, Ataie-Ashtiani \& Nik-Khah (2008b) and Najfi-Jilani \& Ataie-Ashtiani (2008) proposed further empirical formulations aimed at forecasting wave features in both the near field and the far field. The width of the wave tank was about 12 times the landslide width, and the waves were free to propagate also in the rear of the slope that did not span on the whole cross section of the tank. Here we report only the formulation for near field wave amplitude. Ataie-Ashtiani \& Nik-Khah (2008b) and Najfi-Jilani \& Ataie-Ashtiani (2008) used a series of dimensionless groups slightly different from that proposed by Watts et al. (2005) and expressed the near field wave amplitude as follows (hereinafter referred to as NJAA2008):

$$
\eta=\frac{u_{t}^{2}}{a_{0}}\left(a_{1} \mathrm{~S}_{b}^{2}+a_{2} \mathrm{~S}_{b}+a_{3}\right)\left(\frac{|\zeta|}{L}\right)^{b_{1} \ln \left(\mathrm{S}_{b}\right)+b_{2}}
$$

whose parameters $a_{i}$ and $b_{i}$ are reported in Table 4 . Formulation (8) is valid within the following ranges: $15^{\circ}<\alpha<60^{\circ}, 0.008<\mathrm{S}_{b}<0.8,0.26<|\zeta| / L<0.86, \mathrm{D}=1.9$.

Figure 3 shows the computed values against the varying relative submergence $(b /|\zeta|)$ and slope incline $(\alpha)$. It has to be stressed that for underwater landslide the higher the slope (the steeper the incline), the higher the wave amplitude, in contrast with subaerial generated waves.

It has to be noted that empirical formulations for underwater landslide generated waves were developed for rigid landslide and the effect of deformability and porosity is controversial. Watts \& Grilli (2003) suggested that landslide deformation, at least at early stage, does not affect its motion, but preliminary numerical simulations of Grilli \& Watts (2005) showed that landslide deformability is able to increase amplitude and affect waveform of generated waves. On the contrary, experimental investigations of Ataie-Ashtiani \& Nik-Khah (2008b) showed that the slide deformations cause an average reduction of about $20-30 \%$ in energy conversion if compared with rigid slide. The problem should be addressed more in details.

\subsection{Impulse waves propagation alongshore}

The first attempt to analyze wave propagation alongshore was performed in the case of an ideal circular island (Yeh et al., 1994; Briggs et al., 1995a; Liu et al., 1995; Cho \& Liu, 1999; Cho et al., 2004). Motivated by the extreme inundation observed in the rear side of Babi Island (Indonesia) during an earthquake induced tsunami attack (December 12, 1992), the experiments consisted in the study of inundation map around a circular island undertaken

\begin{tabular}{c|c}
\hline$a_{1}$ & $1.44976(\sin \alpha)^{3}-2.02732(\sin \alpha)^{2}+0.71456(\sin \alpha)-0.04967$ \\
\hline$a_{2}$ & $-0.00692(\sin \alpha)^{3}+0.14119(\sin \alpha)^{2}-0.04103(\sin \alpha)+0.00308$ \\
\hline$a_{3}$ & $0.00580(\sin \alpha)^{3}-0.00913(\sin \alpha)^{2}+0.00309(\sin \alpha)+0.00019$ \\
\hline$b_{1}$ & $9.68278(\sin \alpha)^{3}-12.68411(\sin \alpha)^{2}+4.64830(\sin \alpha)-0.65307$ \\
\hline$b_{2}$ & $19.23503(\sin \alpha)^{3}-27.66358(\sin \alpha)^{2}+12.49724(\sin \alpha)-3.72730$ \\
\hline
\end{tabular}

Table 4. Parameters of equation (8) 

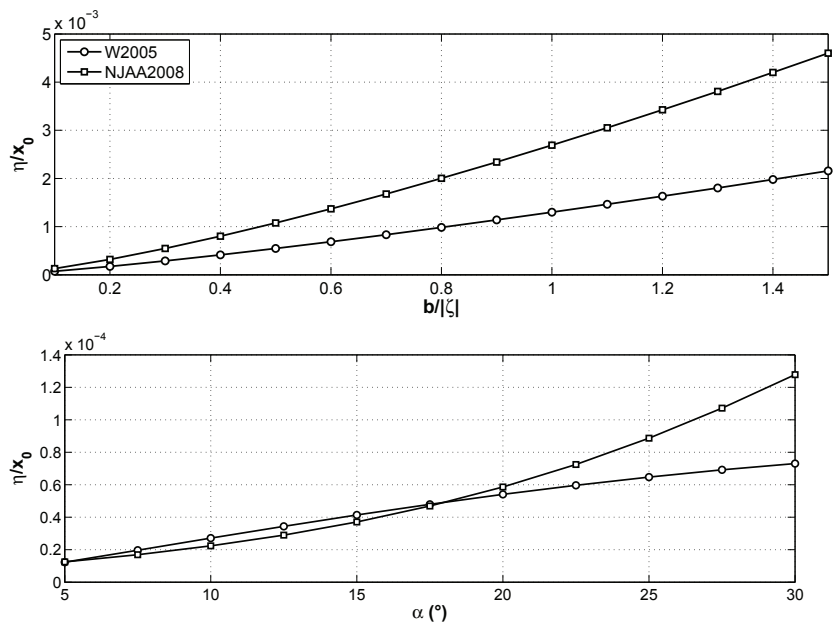

Fig. 3. Computed values of near field wave amplitude $(\eta)$ normalised with characteristic length of landslide motion $\left(x_{0}\right)$. Upper panel: $\alpha=30^{\circ}, \mathrm{S}_{b}=0.1, \mathrm{D}=1.9$. Lowe panel: $\mathrm{S}_{b}=0.1, b /|\zeta|=0.1, \mathrm{D}=1.9$.

to the attack of a solitary wave propagating from offshore. Here we want to pay attention to impulse wave propagation when impulse waves are generated directly on the shore. Indeed, landslide generated waves can remain trapped close to the coast due to refraction phenomena and edge waves occur (Ursell, 1952; Lynett \& Liu, 2005; Johnson, 2007). Ursell (1952) showed that waves on straight coast can remain trapped close to the shoreline depending on the beach slope (edge wave modes). In particular, he showed that the number of possible edge waves modes $n_{M}$ has to satisfy the following relationship

$$
n_{M} \leq \frac{1}{2}\left(\frac{\pi}{2 \alpha}-1\right)
$$

Then, the higher the beach slope, the lower the energy trapped close to the coast. It has to be noted that perfect trapping was demonstrated not possible in a polar-symmetric topography, i.e. for ideal conical island (Renzi \& Sammarco, 2010).

Liu et al. (1998) generated wave trains with a hinged wave-maker moving at the undisturbed shoreline of a straight coast (Liu \& Yeh, 1996, $\alpha=15^{\circ}, \cot \alpha=3.7$ ). Those experiments showed that perturbations occurring at the coast generate dispersive waves, even if in very shallow water. On the basis of standard spectral analysis they argued that near the shoreline the Stokes edge waves (zero-th edge wave mode) dominates and wave energy trapping occur for a long distance. Then, Liu et al. (2005) experimentally reproduced landslides sliding down an incline $\left(\alpha=26.6^{\circ}, \cot \alpha=2\right)$ in a wave tank. The tank was about 4 times the landslide width (triangular section body). They used experimental data to validate a RANS-VOF numerical model and they observed that the sidewalls affected the waves propagating alongshore (i.e. induced wave run-up) just after about 1.5 seconds. After Lynett \& Liu (2005) performed a series of numerical simulations in the case of elliptical solid landslides sliding down a sloping beach, hence characterized by a straight coast. By using of landslide motion law proposed by Watts (1998), they used the numerical results to provide empirical formulations suitable to forecast run-up along the coast for both subaerial and submerged landslides. More in particular, 
they investigated the role of a series of dimensionless parameters: (i) dimensionless landslide thickness $\left(S_{\zeta}=-\tilde{s} / \zeta\right.$, being the origin of $\zeta$ axis located at the undisturbed shoreline, positive upward and $\tilde{s}$ the maximum landslide thickness measured along the vertical direction); (ii) landslide steepness $\left(\mu=2 \pi \tilde{s} / b=k_{s} \tilde{s}\right)$; (iii) symmetry of the landslide $\left(\kappa=b_{f} / b_{b}\right.$, being $b_{f}$ and $b_{b}$ the horizontal distances from the location of maximum landslide thickness forward and backward respectively, $\left.b=b_{f}+b_{b}\right)$; (iv) aspect ratio $(\mathrm{A}=b / w)$; (v) specific gravity $(\mathrm{G})$ and (vi) beach slope $(\alpha)$. They defined a "near-shore" far field, where "edge waves become important", whereas the near field wave pattern is strongly related to the source of impulse waves. In particular they showed that the near field extends up to about 5 times the landslide width for the subaerial case, whereas in the case of underwater landslide, also the aspect ratio of the body plays a key role in the extension of the near field:

$$
\left(\frac{y_{n f}}{w}\right)_{S} \simeq 5 \quad ; \quad\left(\frac{y_{n f}}{w}\right)_{U} \simeq 5\left(\frac{L}{W}\right)
$$

For the underwater case, Lynett \& Liu (2005) provided empirical formulations for the maximum run-up $\left(R_{u}\right)$ and run-down $\left(R_{d}\right)$ immediately landward the landslide centreline:

$$
\begin{aligned}
\frac{R_{u}}{\tilde{s}} & \simeq 0.30 \mathrm{~S}_{\zeta}^{1.16} \mu^{-1.40} \mathrm{~A}^{0.83} \kappa^{-0.015} \mathrm{G}^{0.80}(\tan \alpha)^{1.71} \\
\frac{R_{d}}{\tilde{s}} & \simeq-0.23 \mathrm{~S}_{\zeta} \mu^{-1.19} \mathrm{~A}^{0.87} \kappa^{-0.230} \mathrm{G}^{0.62}(\tan \alpha)^{1.14}
\end{aligned}
$$

At the near-far field division, the run-up reads as follows:

$$
\frac{R_{u}}{\tilde{s}} \simeq 0.07 S_{\zeta} \mu^{-6 / 5} \mathrm{~A}^{5 / 6} \kappa^{-1 / 4} \mathrm{G}^{4 / 3}(\tan \alpha)^{4 / 3}
$$

As the edge waves propagate alongshore, dispersion effects can induce a secondary run-up peak. Numerical simulations of Lynett \& Liu (2005) showed that in some cases this secondary peak can exceed the run-up observed just landward of the landslide centreline. This secondary peak was observed to be located at:

$$
\frac{y_{s p}}{w} \simeq 0.6 \mathrm{~S}_{\zeta}^{-1} \mu^{6 / 5} \mathrm{~A}^{-1} \kappa^{1 / 3} \mathrm{G}^{-1 / 5}(\tan \alpha)^{-6 / 5}
$$

where the run-up can be estimated by the following relationship:

$$
\frac{R_{u}}{\tilde{s}} \simeq 0.17 \mathrm{~S}_{\zeta}^{4 / 3} \mu^{-8 / 5} \mathrm{~A}^{5 / 6} \kappa^{-1 / 3} \mathrm{G}^{3 / 4}(\tan \alpha)^{5 / 3}
$$

In the case of subaerial landslide, only the run-up at the near-far field division was provided:

$$
\frac{R_{u}}{\tilde{s}} \simeq 0.1 S_{\zeta}^{-1 / 4} \mathrm{G}
$$

Validity ranges of the dimensionless relationships proposed by Lynett \& Liu (2005) follow: $0.125<\left|\mathrm{S}_{\zeta}\right|<1.0,0.01<\mu<0.25,0.7<\kappa<1.7,1<\mathrm{A}<10,1.8<\mathrm{G}<3.2,1.9^{\circ}<\alpha<5.7^{\circ}$.

It can be observed that the simulated beach slope ranged from about $2^{\circ}(\cot \alpha=30)$ up to about $6^{\circ}(\cot \alpha=10)$. These values represent typical values of coastal areas, but some steeper slopes can exist where landslides are likely to occur. Such a case occurred at the volcanic island of Stromboli on December 30, 2002 when two landslides generate impulse waves that propagate along the coast of the island itself (Tinti et al., 2005a;b). The slope of the island flank 
is about $18^{\circ}(\cot \alpha=3)$, then quite larger than the slopes simulated by Lynett \& Liu (2005). This event motivated a series of three-dimensional experimental works aimed at reproducing the wave generation by semi-elliptical landslides sliding down plane beaches with straight coasts (Di Risio et al., 2009a) and flanks of conical islands (Di Risio et al., 2008; 2009b; Molfetta et al., 2010).

Di Risio et al. (2009a) carried out a series of experiments in a three-dimensional wave tank where a plane beach was placed. Then the experimental layout was similar to the cases simulated by Lynett \& Liu (2005), but with a steeper beach. Along the beach a semi-elliptical landslide model $(G=1.83)$ were left to slide along the incline. Both partially submerged and subaerial landslide were reproduced (i.e. $0.28<S_{\zeta}<\infty$, being $S_{\zeta}=\infty$ when landslide center mass is located at the undisturbed shoreline elevation). The tank width was about 27 times landslide width, quite larger than previous experimental investigations (Liu et al., 2005; Enet et al., 2003; Enet \& Grilli, 2007). Nevertheless the tank was short in the offshore direction and front sidewalls also reflected generated waves. The experimental layout allowed to observe the near field wave pattern, just landward to the landslide, and the propagation alongshore of the leading wave before the sidewalls reflection contaminated the induced waves. During the experiments the secondary run-up peak was located and the maximum run-up was located at about two times the landslide width away the centreline of the landslide rather than directly landward the landslide. At the near-far field division defined by Lynett \& Liu (2005) they observed that the dimensionless run-up induced by the leading wave was equal to about $R_{u} / s \simeq 0.18$, whilst the maximum run-up was $R_{u} / s \simeq 0.28$, by keeping in mind that the latter could be affected by sidewalls reflection. Although outside the validity range, the formulation (16) gives a value equal to $0.25\left(\mathrm{~S}_{b}=0.28\right)$, quite similar to the observed value. The work by Di Risio et al. (2009b) was aimed at reproducing impulse waves propagation around a conical island, similar to that of Briggs et al. (1995a), placed at the centre of a large wave tank (50 $\mathrm{m}$ long, $30 \mathrm{~m}$ wide, $3 \mathrm{~m}$ high at the Research and Experimentation Laboratory for Coastal Defence - LIC - of the Technical University of Bari, Italy). The landslide model was exactly the same used by Di Risio et al. (2009a). During the experiments, the induced run-up along the coast was measured by means of special gauges directly embedded into the island flanks. Only subaerial landslides were reproduced and the role of undisturbed shoreline radius was investigated: the higher the undisturbed shoreline radius, the higher the induced run-up. The large dimensions of the wave tank allowed to observe the propagation of waves along the whole circular coastline and dispersive features of wave packets were observed, being the maximum run-up induced by the first wave near the generation area, by the second wave up to a curvilinear distance alongshore equal to about 8 times the landslide width, then the third wave induces the maximum run-up and so on. Although based on relatively few data, Di Risio et al. (2008) provided a series of empirical formulations giving the run-up induced by the impulse waves around the island by the first four waves of the generated train:

$$
\begin{gathered}
\frac{R_{u}^{(1)}}{s}=1.049\left(\frac{w}{r_{0}}\right)^{-0.470}\left(\frac{\tilde{y}}{w}\right)^{-2.021} \\
\frac{R_{u}^{(2)}}{s}=0.386\left(\frac{w}{r_{0}}\right)^{-0.066} \exp \left[\left(-0.131 \frac{\tilde{y}}{w}\right)\right] \\
\frac{R_{u}^{(3)}}{s}=0.011\left(\frac{w}{r_{0}}\right)^{-0.945} \exp \left[\left(0.007 \frac{\tilde{y}}{w}\right)^{2}\right]
\end{gathered}
$$




$$
\frac{R_{u}^{(3)}}{s}=0.011\left(\frac{w}{r_{0}}\right)^{-0.341} \exp \left[\left(0.001 \frac{\tilde{y}}{w}\right)^{2}\right]
$$

where $\tilde{y}$ is measured along the undisturbed shoreline (i.e. it is curvilinear coordinate) with radius equal to $r_{0}$. Validity ranges of the above relationships follow: $0.15<w / r_{0}<0.19$, $1<\tilde{y} / w<20$. To date, these are the unique empirical formulations based on experimental data aimed at forecasting wave run-up on island coastlines when a landslide occurs directly on the flank of the island itself.

\section{Impulse wave run-up}

Once impulse waves are generated by landslides, they propagate and interact with water body boundaries. The waves run up the coastal boundaries and induce even large inundations.

Since the earlier work by Hall \& Watts (1953) and Camfield \& Street (1970), a long series of experiments have been carried out in order to forecast the run-up induced by a single impulse wave. Almost all the experiments dealt with solitary waves (breaking or non-breaking). This is due to the fact that solitary wave has been recognized so far as the proper model to describe tsunami approaching shoreline. Actually, Madsen \& Schaffer (2010) has recently shown that this is not realistic for a geophysical tsunami.

For non-breaking solitary waves, Synolakis (1987) found that non-linear and linear shallow water equations for a sloping beach (angle to the horizontal $\beta$ ) connected to an horizontal bottom have the same solution given by:

$$
\frac{R_{u}}{d}=2.831 \sqrt{\cot \beta}\left(\frac{H}{d}\right)^{1.25}
$$

where $H$ is the wave height. The run-up law given by equation (21) is consistent with the Green law (Lamb, 1932, §185), valid for the propagation of waves in a canal of gradually varying rectangular section. This law states the free surface elevation $(\eta)$ is inversely proportional to mean water depth, i. e.:

$$
\eta \propto d^{-1 / 4}
$$

The relationship (21) is valid for non-breaking solitary waves, then a kind of breaking criterion is needed in order to check its validity:

$$
\frac{H}{d}>0.8183(\cot \beta)^{-10 / 9} \text {. }
$$

However, this is not a proper breaking criterion as based on the limit at which the Jacobian of hodograph transformation used by Synolakis (1987) becomes singular. It was noted that the assumptions inherent in the shallow-water wave theory are violated before the Jacobian becomes singular, then it cannot be viewed as the actually point where the waves break but a validity limit for analytical results (Meyer, 1986a;b). Indeed, numerical simulations of Grilli et al. (1997) showed that solitary waves break during climbing on sloping beach if

$$
\frac{H}{d}>16.9(\tan \beta)^{2} \text {. }
$$

The analytical method of Synolakis (1987) has been used by Li \& Raichlen (2001) that retained higher order terms in the initial condition. Then a corrected run-up law for non-breaking solitary waves has been defined:

$$
\frac{R_{u}}{d}=2.831 \sqrt{\cot \beta}\left(\frac{H}{d}\right)^{5 / 4}+0.293(\cot \beta)^{3 / 2}\left(\frac{H}{d}\right)^{9 / 4}
$$


A first attempt to provide a reliable formulation for run-up forecasting induced by other waves than solitary one was made by Tadepalli \& Synolakis (1994). They provided analytical relationships giving induced run-up in the case of leading-elevation and leading-depression generalized, isoscele and double N-waves. The maximum run-up was showed to be induced by leading-depression isosceles and double $\mathrm{N}$-waves given by:

$$
\frac{R_{u}}{d}=3.86 \sqrt{\cot \beta}\left(\frac{H}{d}\right)^{1.25} \quad ; \quad \frac{R_{u}}{d}=4.55 \sqrt{\cot \beta}\left(\frac{H}{d}\right)^{1.25}
$$

respectively. It has to be noted that the resulting run-up is higher than the one induced by the solitary wave.

Nevertheless many other researches still preferred to focus on the run-up induced by solitary waves by making use of different approaches. Li \& Raichlen (2003) proposed a simple energy model that gives a reliable estimation of the run-up resulting from breaking solitary waves by taking into account also the shape of the run-up tongue:

$$
\frac{R_{u}}{d}=\frac{1-E_{b} / E_{i}}{1.5 k_{t}}\left(\frac{H}{d}\right)
$$

where $E_{b}$ and $E_{i}$ are the dissipated energy by breaking processes and incident solitary wave energy respectively and $k_{t}$ is the shape factor of the run-up tongue $\left(k_{t}=0.33\right.$ for a triangular run-up tongue, $k_{t}=0.12$ based on numerical simulation by $\mathrm{Li}, 2000, k_{t}=0.18$ based on experimental data). For the ratio $E_{b} / E_{i}$ numerical simulations by $\operatorname{Li}(2000)$ have been used by Li \& Raichlen (2003):

$$
\frac{E_{b}}{E_{i}}=C[A \ln (\cot \beta)+B]
$$

with

$$
A=-0.470\left(\frac{H}{d}\right)+0.534 \quad ; \quad B=2.165\left(\frac{H}{d}\right)-1.154 \quad ; \quad C=0.190\left[\ln \left(\frac{H}{d}\right)\right]+0.969 .
$$

Gedik et al. (2005) performed an experimental investigation aimed at including the influences of sand grain diameter $\left(d_{s}\right)$ for sloping sandy beach, also in the case of armored beaches (armor units diameter $\left.d_{n 50}\right)$ :

$$
\frac{R_{u}}{d}=4 \cdot 10^{-4}\left(\frac{H}{d_{s}} D \cot \beta\right)^{0.921} \quad ; \quad \frac{R_{u}}{d}=5 \cdot 10^{-3}\left(\frac{H}{d_{n 50}} D \cot \beta\right)^{0.954}
$$

Hughes (2004a) used experimental and numerical data of past studies (Hall \& Watts, 1953; Li, 2000; Briggs et al., 1995b; Synolakis, 1986; 1987) in order to define empirical formulation for breaking and non-breaking solitary wave run-up based on the wave momentum flux parameter proposed by Hughes (2004b).

It has to be noted that the formulations cited above are almost all related to solitary waves. However, when impulse waves are generated by landslides, especially in enclosed basins (i.e. reservoirs), the waveform is likely to be related to other wave types (e.g. Panizzo et al., 2005a). Recently, on the basis of the definition of representative solitary wave period (Kobayashi \& Karjadi, 1994), it has been demonstrated that the role of the relative wave height $(H / d)$ for solitary wave run-up (relative to wave height $R_{u} / H$ ) is replaced by the dimensionless wave period $(T \sqrt{g / d})$ for oscillatory waves, whilst the role of beach slope remains unchanged 
(Fuhrman \& Madsen, 2008; Madsen \& Fuhrman, 2008). Then, a general relationship that gives impulse wave run-up can be formally expressed as follows:

$$
\frac{R_{u}}{H}=a_{1}\left(\frac{H}{d}\right)^{a_{2}}\left(T \sqrt{\frac{g}{d}}\right)^{a_{3}}(\tan \beta)^{a_{4}} .
$$

For solitary wave run-up $a_{3}=0$, whereas for sinusoidal (linear) waves $a_{2}=0$. Run-up law proposed by Synolakis (1987) reads $a_{1}=2.831, a_{2}=+1 / 4, a_{3}=0$ and $a_{4}=-1 / 2$. Consistently, Green Law can be recasted by keeping $a_{1} \neq 0, a_{2}=+1 / 4, a_{3}=0, a_{4} \neq 0$.

Muller (1995) performed a series of experimental tests providing the following empirical formulation:

$$
\frac{R_{u}}{H}=1.25\left(\frac{H}{d}\right)^{0.25}\left(\frac{H}{\lambda}\right)^{-0.15}\left(\frac{\pi}{2 \beta}\right)^{0.20}
$$

The experimental ranges of the above relationship follow: $0.011<H / d<0.521,0.001<H / \lambda<$ $0.013,18.4^{\circ}<\beta<90^{\circ}$. It has to be stressed that the wavelength $\lambda$ estimation is needed in order to use the formulations (32). Hence, it can be used only if also wave celerity estimate is available, for instance by using solitary wave celerity (Boussinesq, 1872).

In order to overcome the shortcomings of relationship (32), Di Risio (2005) performed a series of two dimensional tests by providing the following formulations for wave run-up:

$$
\frac{R_{u}}{H}=1.37\left(\frac{H}{d}\right)^{0.51}\left(T \sqrt{\frac{g}{d}}\right)^{0.47}(\sin \beta)^{0.26}
$$

This formulation is consistent with theoretical reasoning of Fuhrman \& Madsen (2008), equation (31), and it is the first empirical formulation involving the wave period. Experimental ranges of relationship (33) follow: $0.18<H / d<0.70,7.48<T \sqrt{g / d}<15.60,22^{\circ}<\beta<84^{\circ}$. Equation (33) can be used also for solitary waves by defining the representative wave period $T_{S}$ as the time interval during which the normalized solitary wave surface elevation $(\eta / H)$ exceeds some small threshold level (Kobayashi \& Karjadi, 1994; Fuhrman \& Madsen, 2008):

$$
T_{S}=1.03 \sqrt{\frac{16 d^{2}}{3 H g(1+H / d)}} .
$$

\section{Impulse wave overtopping}

If the induced run-up exceeds the dam free-board $(\xi)$ the water will overtop the structure, and floods the downstream areas. In this case, overtopping volume and overtopping flow forecasting can be precious in modeling downstream flooding (e.g. Risley et al., 2006).

To date, some analytical solutions exist for bore waves (e.g. Peregrine \& Williams, 2001; Baldock et al., 2005). The only researches dealing with dam overtopping due to impulse waves are those of Muller (1995) and Di Risio (2005). The former performed a series of two-dimensional experiments by reproducing the effect of both the dam slope and crest width. The following empirical formulation was given for the overtopping volume per unit width:

$$
\frac{V}{d^{2}}=1.45 \tilde{\kappa}\left(\frac{H}{d}\right)^{1.33}\left(T \sqrt{\frac{g}{d}}\right)^{0.44}\left(1-\frac{\xi}{R_{u}}\right)^{2.2}
$$


For small dam crest width (relative to impulse wave height) the coefficient $\tilde{\kappa}$ is equal to 0.53 , 0.61 and 0.66 for $\beta$ equal to $90^{\circ}, 45^{\circ}$ and $18.4^{\circ}$ respectively. It has to be noted that equation (35) can be used once one has estimated the wave run-up. Muller (1995) provided also the time duration $\tilde{t}_{0}$ of the overtopping event, even if only in the case of $\xi=0$, then giving an estimate of maximum overtopping discharge per unit width $q_{0}=V_{0} / \tilde{t}_{0}$ :

$$
\tilde{t}_{0}=4\left(T \sqrt{\frac{g}{d}}\right)^{0.44}
$$

It can be observed that the overtopping discharge $\left(q_{0}=V_{0} / t_{0}\right)$ does not depend upon wave period. Experimental ranges of equation (35) follow: $0.019<H / d<0.488,9.0<T \sqrt{g / d}<21.0$. In a similar way, Di Risio (2005) performed two-dimensional experiments giving the following empirical formulation:

$$
\frac{V}{d^{2}}=0.0084\left(\frac{H}{d}\right)^{3.18}\left(T \sqrt{\frac{g}{d}}\right)^{1.58}\left(\frac{\xi}{d}\right)^{-1.62}(\sin \beta)^{-0.61}
$$

with the experimental ranges $0.18<H / d<0.70,7.48<T \sqrt{g / d}<15.60,22^{\circ}<\beta<84^{\circ}, 0.09<$ $\xi / d<1.42$.

\section{Concluding remarks}

A comprehensive review of landslide generated wave forecasting has been presented. The review covers the overall phenomenon, from wave generation up to wave propagation both alongshore and offshore and impulse wave interaction with coasts and dam (i.e. run-up and overtopping).

The main aim of the work is to review empirical formulations useful to practically forecast generated wave features (i.e. maximum wave height, crest amplitude and period; leading wave height, crest amplitude and period) both in the near and far field. Furthermore attention has been paid to the propagation alongshore when landslides generate waves directly at the coast and edge waves modes can be triggered. The interaction of impulse waves with water body boundaries has been described in terms of wave run-up and dam overtopping.

Some aspects related to generation phenomena have to be addressed. In particular, the applicability of empirical formulations based on solid landslide experiments should be investigated with respect to the role of deformations and porosity on wave generation, especially in the case of underwater landslide that seems to be controversial.

\section{Acknowledgments}

The physical modeling performed by the authors and described in the present chapter were funded by the RID (National Dam Office of the Italian Government), by the MIUR (Italian Minister of Formation, University and Research) and by Dipartimento Nazionale della Protezione Civile (Italian Department for Civil Protection). The authors wish to thanks all the people who participate to the experimental investigations. In particular Mr. M. Nardi and L. Matergia, the LIAM technicians, are acknowledged. Furthermore Eng. M. G. Molfetta, F. Aristodemo, A. Romano, G. Bellotti and A. Panizzo are acknowledged for their cooperation during experimental investigations and data analysis on conical island and planar beach. 


\section{References}

Ataie-Ashtiani, B. \& Nik-Khah, A. (2008a). Impulse waves caused by subaerial landslides, Environ. Fluid Meach. 8(3): 263-280, doi:10.1007/s10652-008-9074-7.

Ataie-Ashtiani, B. \& Nik-Khah, A. (2008b). Laboratory investigations on impulsive waves caused by underwater landslide, Coast. Eng. 55(12): 989-1004, doi: 10.1016/j.coastaleng.2008.03.003.

Baldock, T., Hughes, M., Daya, K. \& Louysa, J. (2005). Swash overtopping and sediment overwash on a truncated beach, Coast. Eng. 52(7): 633-645, doi: 10.1016/j.coastaleng.2005.04.002.

Boussinesq, J. (1872). Theorie des ondes et des remous que se propagent le long d'un canal rectangulaire horizontal, en communiquant au liquide contenu dans ce canal des vitesses sensiblement pareilles de la surface au fond, J. Math. Pures Appl. 17: 55-108.

Bowering, R. J. (1970). Landslide generated waves: a laboratory study, Master's thesis, Queen's University, Kingston, Ontario, Canada.

Briggs, M. J., Synolakis, C. E., Harkins, G. S. \& Green, D. R. (1995a). Laboratory experiments of tsunami runup on a circular island, Pure Appl. Geophys. 144(3/4): 569-593, doi: 10.1007/BF00874384.

Briggs, M. J., Synolakis, C. E., Harkins, G. S. \& Hughes, S. A. (1995b). Large-scale, three-dimensional laboratory measurements of tsunami inundation, Tsunamis: Progress in Prediction, Disaster Prevention and warning., Kluver Academic Publishers, pp. 129-149, ISBN: 0-7923-3483-3.

Camfield, F. E. \& Street, R. L. (1970). Shoaling of solitary waves on small slopes, J. of the Waterways and Harb. Div., Proc. of the Am. Soc. of Civil Eng. 95(WW1): 1-22.

Cea, L., Ferreiro, A., Vazquez-Cendon, M. E. \& Puertas, J. (2004). Experimental and numerical analysis of solitary waves generated by bed and boundary movements, Int. J. Numer. Meth. Fl. 46(8): 793-813, doi: 10.1002/fld.774.

Chaudhry, M. H., Mercer, A. G. \& Cass, D. (1983). Modeling of slide-generated waves in a reservoir, J. Hydraul. Eng.-ASCE 109(11): 1505-1520, doi: 10.1061/(ASCE)0733-9429(1983)109:11(1505).

Cho, Y. S. \& Liu, P. L.-F. (1999). Crest-length effects in nearshore tsunami run-up around island, J. Geophys. Res. 104(C4): 7907-7913, doi: 10.1029/1999JC900012.

Cho, Y.-S., Park, K.-Y. \& Lin, T.-H. (2004). Run-up heights of nearshore tsunamis based on quadtree grid system, Ocean Eng. 31(8-9): 1093-1109, doi: 10.1016/j.oceaneng.2003.10.011.

Davidson, D. D. \& McCartney, B. L. (1975). Water waves generated by landslides in reservoirs, J. of the Hydraul. Div., Proc. of the Am. Soc. of Civil Eng. 101(HY12): 1489-1501.

de Carvalho, R. F. \& do Carmo, A. J. S. (2007). Landslides into reservoirs and their impacts on banks, Environ. Fluid Mech. 7(6): 481-493, doi: 10.1007/s10652-007-9039-2.

Di Risio, M. (2005). Landslide generated impulsive waves: generation, propagation and interaction with plane slopes. An experimental and analytical study, PhD thesis, University of Roma Tre, Rome.

Di Risio, M. \& Sammarco, P. (2008). Analytical modeling of landslide-generated waves, J. Waterway, Port, Coastal, Ocean Eng. 134(1): 53-60, doi: 10.1061/(ASCE)0733-950X(2008)134:1(53).

Di Risio, M., Bellotti, G., Panizzo, A., Molfetta, M. G., Aristodemo, F., De Girolamo, P., Pratola, L. \& Petrillo, A. F. (2008). Tsunamis generated by landslide along the coast of a conical island: new three-dimensional experiments, Proc. of 31st International Conference of 
Coastal Engineering, Vol. 2, pp. 1396-1408, doi: 10.1142/9789814277426_0116.

Di Risio, M., Bellotti, G., Panizzo, A. \& De Girolamo, P. (2009a). Three-dimensional experiments on landslide generated waves at a sloping coast, Coast. Eng. 56(5-6): 659-671, doi: 10.1016/j.coastaleng.2009.01.009.

Di Risio, M., De Girolamo, P., Bellotti, G., Panizzo, A., Aristodemo, F., Molfetta, M. G. \& Petrillo, A. F. (2009b). Landslide-generated tsunamis runup at the coast of a conical island: new physical model experiments, J. Geophys. Res. 114, C01009, 16 pp, doi: 10.1029/2008JC004858.

Enet, F., Grilli, S. T. \& Watts, P. (2003). Laboratory experiments for tsunami generated by underwater landslides: comparison with numerical modeling, Proc. of the Thirteenth Int. Offshore and Polar Eng. Conf., Honolulu, Hawaii, USA, May 25-30, pp. 372-379.

Enet, F. \& Grilli, S. T. (2007). Experimental study of tsunami generation by three-dimensional rigid underwater landslides, J. Waterway, Port, Coastal, Ocean Eng. 133(6): 442-454, doi: 10.1061/(ASCE)0733-950X(2007)133:6(442).

Fleming, J. G., Walters, R. A., Sue, L. P. \& Nokes, R. I. (2005). Experimental design for solid block and granular submarine landslides: a unified approach, Tsunamis: case studies and Recent Developments, Springer, K. Satake (ed.), pp. 259-277, doi: 10.1007/1-4020-3331-1_16.

Fritz, H. M., Hager, W. H. \& Minor, H. E. (2001). Lituya bay case: rockslide impact and wave run-up, Science of Tsunami Hazards 19(1): 3-22.

Fritz, H. M., Hager, W. H. \& Minor, H. E. (2003a). Landslide generated impulse waves. 1. Instantaneous flow fields, Exp. Fluids 35(6): 505-519, doi: 10.1007/s00348-003-0659-0.

Fritz, H. M., Hager, W. H. \& Minor, H. E. (2003b). Landslide generated impulse waves. 2. Hydrodynamic impact craters, Exp. Fluids 35(6): 505-519, doi: 10.1007/s00348-003-0660-7.

Fritz, H. M., Hager, W. H. \& Minor, H. E. (2004). Near field characteristics of landslide generated impulse waves, J. Waterway, Port, Coastal, Ocean Eng. 130(6): 287-302, doi: 10.1061/(ASCE)0733-950X(2004)130:6(287).

Fritz, H. M., Mohammed, F. \& Yoo, J. (2009). Lituya bay landslide impact generated mega-tsunami 50th anniversary, Pure Appl. Geophys. 166(1-2): 153175, doi: 10.1007/s00024-008-0435-4.

Fuhrman, D. R. \& Madsen, P. A. (2008). Surf similarity and solitary wave runup, J. Waterway, Port, Coastal, Ocean Eng. 134(3): 195-198, doi: 10.1061/(ASCE)0733-950X(2008)134:3(195).

Gedik, N., Irtem, E. \& Kabdasli, S. (2005). Laboratory investigation on tsunami run-up, Ocean Eng. 32(5-6): 513-528, doi: 10.1016/j.oceaneng.2004.10.013.

Goring, D. G. (1978). Tsunamis. The propagation of long waves onto a shelf., PhD thesis, California Institute of Technology, Pasadena, California.

Grilli, S., Svendsen, I. \& Subramanya, R. (1997). Breaking criterion and characteristics for solitary waves on slope, J. Waterway, Port, Coastal, Ocean Eng. 123(3): 102-112, doi: 10.1061/(ASCE)0733-950X(1997)123:3(102).

Grilli, S. T. \& Watts, P. (2005). Tsunami generation by submarine mass failure. I: modeling, experimental validation, and sensitivity analyses, J. Waterway, Port, Coastal, Ocean Eng. 131(6): 283-297, doi: 10.1061/(ASCE)0733-950X(2005)131:6(283).

Hall, J. V. \& Watts, J. W. (1953). Laboratory investigation of the vertical rise of solitary waves on impermeable slopes, Technical Memorandum 33, Beach Erosion Board, US Army Corps of Engineers. 
Heinrich, P. (1992). Nonlinear water waves generated by submarine and aerial landslides, J. Waterway, Port, Coastal, Ocean Eng. 118(3): 249-266, doi: 10.1061/(ASCE)0733-950X(1992)118:3(249).

Heller, V., Hager, W. H. \& Minor, H.-E. (2008). Scale effects in subaerial landslide generated impulse waves, Exp. Fluids 44(5): 691-703, doi: 10.1007/s00348-007-0427-7.

Heller, D. \& Kinnear, R. D. (2010a). Discussion of “Experimental investigation of impact generated tsunami; related to a potential rock slide, western norway" by G. Sælevik, A. Jensen, G. Pedersen [Coastal Eng. 56 (2009) 897-906], Coast. Eng. 57(8): 773-777, doi: 10.1016/j.coastaleng.2010.02.008.

Heller, D. \& Hager, W. H. (2010b). Impulse product parameter in landslide generated impulse waves, J. Waterway, Port, Coastal, Ocean Eng. 136(3): 145-155, doi: 10.1061/(ASCE)WW.1943-5460.0000037.

Huber, A. (1980). Schwallwellen in seen als floge von felssturzen (reservoir impulse waves caused by rockfall), Technical Report Mitteilung 47, Laboratory of Hydraulics, Hydrology and Glaciology, Swiss Federal Institute of Technology.

Huber, A. (1982). Impulse waves in swiss lakes as a results of rock avalanches and bank slides. experimental results for the prediction of the characteristic numbers of these waves., Comminsion Internationale des Grands Barrages, 14 Congres des Grand Barrages, Rio de Janeiro, 1982, pp. 311-390.

Huber, A. \& Hager, W. H. (1997). Forecasting impulse waves in reservoirs, Comminsion Internationale des Grands Barrages, 19 Congres des Grand Barrages, Florence, 1997, pp. 993-1005.

Hughes, S. A. (2004a). Estimation of wave run-up on smooth, impremeable slopes using the wave momentum flux parameter, Coast. Eng. 51(11-12): 1085-1104, doi: 10.1016/j.coastaleng.2004.07.026.

Hughes, S. A. (2004b). Wave momentum flux parameter: a descriptor for nearshore waves, Coast. Eng. 51(11-12): 1067-1084, doi: 10.1016/j.coastaleng.2004.07.025.

Iwasaki, S. (1983). Experimental study of a tsunami generated by a horizontal motion of a sloping bottom, Bull. of the Earthq. Res. Inst. 57: 239-262.

Johnson, R. S. (2007). Edge waves: theories past and present, Phil. Trans. R. Soc. A 365(1858): 2359-2376, doi: 10.1098/rsta.2007.2013.

Kamphuis, J. W. \& Bowering, R. J. (1970). Impulse waves generated by landslide, Proc. of 12th Coastal Engineering Conference, pp. 575-588.

Kattel, G. \& Eric, B. (2002). Accuracy of solitary wave generation by a piston wave maker, J. of Hydraul. Res. 40(3): 321-331, doi: 10.1080/00221680209499946.

Kobayashi, N. \& Karjadi, E. A. (1994). Surf-similarity parameters for breaking solitary-wave runup, J. Waterway, Port, Coastal, Ocean Eng. 120(6): 645-650, doi: 10.1061/(ASCE)0733-950X(1994)120:6(645).

Koo, W. \& Kim, M.-H. (2008). Numerical modeling and analysis of waves induced by submerged and aerial/sub-aerial landslides, KSCE J. Civ. Eng. 12(2): 77-83, doi: 10.1007/s12205-008-0077-1.

Lamb, H. (1932). Hydrodynamics, 6th edn, Dover Publications, Inc., ISBN: 0-486-60256-7.

Li, Y. (2000). Tsunamis: non-breaking and breaking solitary wave runup, Technical Report KH-R-60, W.M. Keck Laboratory of Hydraulics and Water Resource, California Institute of Technology, Pasadena, California.

Li, Y. \& Raichlen, F. (2001). Solitary wave runup on plane slope, J. Waterway, Port, Coastal, Ocean Eng. 127(1): 33-44, doi: 10.1061/(ASCE)0733-950X(2001)127:1(33). 
Li, Y. \& Raichlen, F. (2003). Energy balance model for breaking solitary wave runup, J. Waterway, Port, Coastal, Ocean Eng. 129(2): 47-59, doi: 10.1061/(ASCE)0733-950X(2003)129:2(47).

Liu, P. L.-F., Cho, Y. S., Briggs, M. J., Kanoglu, U. \& Synolakis, C. E. (1995). Runup of solitary waves on a circular island, J. Fluid Mech. 302: 259-285, doi: 10.1017/S0022112095004095.

Liu, P. L.-F. \& Yeh, H. H. (1996). The generation of edge waves by a wave-maker, Physics of Fluids 8(8): 2060-2065, doi: 10.1063/1.869008.

Liu, P. L.-F., Yeh, H., Lin, P., Chang, K. T. \& Cho, Y. S. (1998). Generation and evolution of edge-wave packets, Physics of Fluids 10(7): 1635-1657, doi: 10.1063/1.869682.

Liu, P. L.-F., Wu, T.-R., Raichlen, F., Synolakis, C. E. \& Borrero, J. C. (2005). Runup and rundown generated by three-dimenional sliding masses, J. Fluid Mech. 536: 107-144, doi: $10.1017 /$ S0022112005004799.

Lynett, P. \& Liu, P. L.-F. (2005). A numerical study of the run-up generated by three-dimensional landslides, J. Geophys. Res. 110, C03006, 16 pp., doi: 10.1029/2004JC002443.

Madsen, P. A. \& Fuhrman, D. R. (2008). Run-up of tsunamis and long waves in terms of surf-similarity, Coast. Eng. 55(3): 209-223, doi: 10.1016/j.coastaleng.2007.09.007.

Madsen, P. A. \& Schaffer, H. A. (2010). Analytical solutions for tsunami runup on a plane beach: single waves, N-waves and transient waves, J. Fluid Mech. 645: 27-57, doi: 10.1017/S0022112009992485.

Malek-Mohammadi, S. \& Testik, F. Y. (2010). New methodology for laboratory generation of solitary waves, J. Waterway, Port, Coastal, Ocean Eng. 136(5): 286-294, doi: 10.1061/(ASCE)WW.1943-5460.0000046.

Mallet, R. \& Mallet, J. W. (1858). Fourth report upon the facts and theory of earthquake phenomena, Transaction of the British Association for the Advancement of Science, 1852 to 1858, Taylor and Francis, Red Lion Court, Fleet Street.

Meyer, R. E. (1986a). On the shore singularity of water-waves. I. The local model, Physics of Fluids 29(10): 3152-3163, doi: 10.1063/1.865967.

Meyer, R. E. (1986b). On the shore singularity of water-waves. II. Small waves do not break on gentle beaches, Physics of Fluids 29(10): 3164-3173, doi: 10.1063/1.865968.

Miller, D. J. (1960). Giant waves in lituya bay, alaska, Geological Survey Professional Paper 354-C. US Government Printing Office, Washington DC.

Miller, R. L. (1970). Prediction curves for waves near the source of an impulse, Proc. of 12th Coastal Engineering Conference, pp. 609-624.

Milne, J. (1898). Earthquakes and other Earth movements, Paul, Trench, Trubner \& Co., London.

Molfetta, M. G., Di Risio, M., Bellotti, G., Romano, A., Pratola, L., De Girolamo, P. \& Damiani, L. (2010). Tsunamis generated by landslides along the coast of a conical island: a new set of three-dimensional experiments, Coastlab2010, Accepted Abstract.

Monaghan, J. J. \& Kos, A. (2000). Scott Russell's wave generator, Phys. Fluids 12(3): 622-630, doi: $10.1063 / 1.870269$.

Montessus de Ballore, F. (1907). La science seismologique, A. Colin, Paris.

Muller, D. (1995). Auflaufen und uberschwappen von impulswellen an talsperren (run-up and overtopping of impulse waves at dams), Technical Report Mitteilung 137, Laboratory of Hydraulics, Hydrology and Glaciology, Swiss Federal Institute of Technology.

Najfi-Jilani, A. \& Ataie-Ashtiani, B. (2008). Estimation of near-field characteristics of tsunami generation by submarine landslide, Ocean Eng. 35(5-6): 545-557, doi: 10.1016/j.oceaneng.2007.11.006.

Noda, E. K. (1970). Water waves generated by landslides, J. of the Waterways and Harb. Div., 
Proc. of the Am. Soc. of Civ. Eng. 96(WW4): 835-855.

Panizzo, A., Bellotti, G. \& De Girolamo, P. (2002). Application of wavelet transform analysis to landslide generated waves, Coast. Eng. 44(4): 321-338, doi: 10.1016/S0378-3839(01)00040-0.

Panizzo, A., De Girolamo, P. \& Petaccia, A. (2005a). Forecasting impulse waves generated by subaerial landslide, J. Geophys. Res. 110, C12025, 23 pp., doi: 10.1029/2004JC002778.

Panizzo, A., De Girolamo, P., Di Risio, M., Maistri, A. \& Petaccia, A. (2005b). Great landslide events in italian artificial reservoir, Natural Hazards and Earth System Science 5: 733-740, SRef-ID: 1684-9981/nhess/2005-5-733.

Pelinovsky, E. \& Poplavsky, A. (1996). Simplified model of tsunami generation by submarine lanslides, Phys. Chem. Earth 21(1-2): 13-17, doi: 10.1016/S0079-1946(97)00003-7.

Peregrine, D. H. \& Williams, S. M. (2001). Swash overtopping a truncated plane beach, J. Fluid Mech. 440: 391-399, doi: 10.1017/S002211200100492X.

Prins, J. E. (1958). Characteristics of waves generated by a local disturbance, Trans. Am. Geoph. Un. 39(5): 865-874.

Renzi, E. \& Sammarco, P. (2010). Landslide tsunamis propagating around a conical island, J. Fluid Mech. 650: 251-285, doi: 10.1017/S0022112009993582.

Risley, J. C., Walder, J. S. \& Denlinger, R. P. (2006). Usoi dam wave overtopping and flood routing in the Bartang and Panj Rivers, Tajikistan, Natural Hazards 38(3): 375-390, doi: 10.1007/s11069-005-1923-9.

Russell, J. S. (1838). Report of the committee on waves, Rep. 7th Meeting British Association Advanced Science, Liverpool, 1837, pp. 417-496.

Russell, J. S. (1845). Report on waves, Rep. 14th Meeting British Association Advanced Science, York, 1844, pp. 311-390.

Sæ levik, G., Jensen, A. \& Pedersen, G. (2009). Experimental investigation of impact generated tsunami; related to a potential rock slide, western norway, Coast. Eng. 56(9): 897-906, doi: 10.1016/j.coastaleng.2009.04.007.

Savage, S. B. \& Hutter, K. (1989). The motion of a finite mass of granular material down a rough incline, J. Fluid Mech. 199: 177-215, doi: 10.1017/S0022112089000340.

Sue, L. P., Nokes, R. I. \& Walters, R. A. (2006). Experimental modeling of tsunami generated by underwater landslides, Science of Tsunami Hazards 24(4): 267-287.

Sue, L. P. (2007). Modelling of tsunami generated by submarine landslides, PhD Thesis, University of Canterbury, Christchurch, New Zealand.

Synolakis, C. E. (1986). The runup of long waves, PhD thesis, California Institute of Technology, Pasadena, California.

Synolakis, C. E. (1987). The runup of solitary waves, J. Fluid Mech. 185: 523-545, doi: 10.1017/S002211208700329X.

Synolakis, C. E. (1990). Generation of long waves in the laboratory, J. Waterway, Port, Coastal, Ocean Eng. 116(2): 252-266, doi: 10.1061/(ASCE)0733-950X(1990)116:2(252).

Synolakis, C. E., Bardett, J. P., Borrero, J. C., Davies, H. L., Okal, E. A., Silver, E. A. \& Sweet, S. Tappin, D. R. (2002). The slump origin of the 1998 papua new guinea tsunami, Proc. R. Soc. Lond. A 458(2020): 763-789, doi: 10.1098/rspa.2001.0915.

Synolakis, C. E. \& Bernard, E. N. (2006). Tsunamis science before and beyond boxing day 2004, Phil. Trans. R. Soc. A 364(1845): 2231-2265, doi: 10.1098/rsta.2006.1824.

Tadepalli, S. \& Synolakis, C. E. (1994). The run-up of n-waves on sloping beach, Proc. R. Soc. Lond. A 445: 99-112.

Tinti, S., Manucci, A., Pagnoni, G., Armigliato, A. \& Zaniboni, F. (2005a). The 30 december 
2002 landslide-induced tsunamis in stromboli: Sequence of the events reconstructed from the eyewitness accounts, Nat. Hazards Earth Syst. Sci. 5: 763-775, SRef-ID: 1684-9981/nhess/2005-5-763.

Tinti, S., Maramai, A., Armigliato, A., Graziani, L., Manucci, A., Pagnoni, G. \& Zaniboni, F. (2005b). Observations of physical effects from tsunamis of december 30, 2002 at stromboli volcano, southern italy, Bull. Volcanol. 68(5): 450-461, doi: 10.1007/s00445-005-0021-x.

Tuck, E. O. \& Hwang, L. S. (1972). Long wave generation on a sloping beach, J. Fluid Mech. 51(3): 449-461, doi: 10.1017/S0022112072002289.

Ursell, F. (1952). Edge waves on a sloping beach, Proc. R. Soc. Lond. A 214(1116): 569-593, doi: 10.1098/rspa.1952.0152.

Walder, J. S., Watts, P., Sorensen, O. E. \& Janssen, K. (2003). Tsunamis generated by subaerial mass flows, J. Geophys. Res. 108(B5), 2236, 19 pp., doi: 10.1029/2001JB000707.

Watts, P. (1998). Wavemaker curves for tsunamis generated by underwater landslides, J. Waterway, Port, Coastal, Ocean Eng. 124(3): 127-137, doi: 10.1061/(ASCE)0733-950X(1998)124:3(127).

Watts, P. (2000). Tsunami features of solid block underwater landslides, J. Waterway, Port, Coastal, Ocean Eng. 126(3): 144-152, doi: 10.1061/(ASCE)0733-950X(2000)126:3(144).

Watts, P., Imamura, F. \& Grilli, S. (2000). Comparing model simulations of three benchmark tsunami generation cases, Science of Tsunami Hazards 18(2): 107-123.

Watts, P. \& Grilli, S. T. (2003). Underwater landslide shape, motion, deformation, and tsunami generation, Proc. of the Thirteenth International Offshore and Polar Engineering Conference, Honolulu, Hawaii, USA, May 25-30, pp. 364-371.

Watts, P., Grilli, S. T., Tappin, D. R. \& Fryer, G. J. (2005). Tsunami generation by submarine mass failure. I: predictive equations and case studies, J. Waterway, Port, Coastal, Ocean Eng. 131(6): 298-310, doi: 10.1061/(ASCE)0733-950X(2005)131:6(298).

Wiegel, R. L. (1955). Laboratory studies of gravity waves generated by the movement of a submerged body, Trans. Am. Geoph. Un. 36(5): 759-774.

Wiegel, R. L., Noda, E. K., Kuba, E. M., Gee, D. M. \& Tornberg, G. F. (1970). Water waves generated by landslides in reservoir, J. of the Waterways and Harb. Div., Proc. of the Am. Soc. of Civ. Eng. 96(WW2): 307-333.

Yeh, H., Liu, P., Briggs, M. \& Synolakis, C. (1994). Propagation and amplification of tsunamis at coastal boundaries, Nature 372: 353-355, doi: 10.1038/372353a0.

Yim, S. C., Yuk, D., Panizzo, A., Di Risio, M. \& Liu, P.-F. (2008). Numerical simulation of wave generation by a vertical plunger using rans and sph models, J. Waterway, Port, Coastal, Ocean Eng. 134(3): 143-159, doi: 10.1061/(ASCE)0733-950X(2008)134:3(143).

Zweifel, A. (2004). Impulswellen: Effekte der Rutschdichte und der Wassertiefe, PhD thesis, ETH Zurich, Zurich (in German).

Zweifel, A., Hager, W. H. \& Minor, H.-E. (2006). Plane impulse waves in reservoirs, J. Waterway, Port, Coastal, Ocean Eng. 132(5): 358-368, doi: 10.1061/(ASCE)0733-950X(2006)132:5(358). 


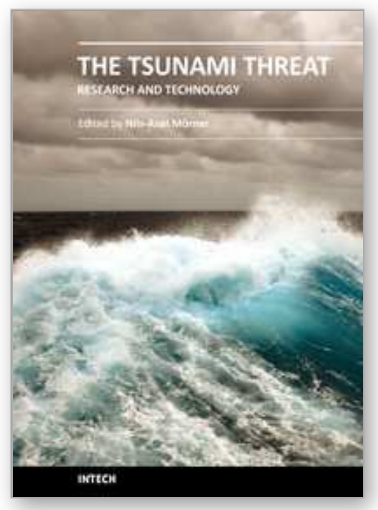

\author{
The Tsunami Threat - Research and Technology \\ Edited by Nils-Axel MÃ $\Uparrow$ rner
}

ISBN 978-953-307-552-5

Hard cover, 714 pages

Publisher InTech

Published online 29, January, 2011

Published in print edition January, 2011

Submarine earthquakes, submarine slides and impacts may set large water volumes in motion characterized by very long wavelengths and a very high speed of lateral displacement, when reaching shallower water the wave breaks in over land - often with disastrous effects. This natural phenomenon is known as a tsunami event. By December 26, 2004, an event in the Indian Ocean, this word suddenly became known to the public. The effects were indeed disastrous and 227,898 people were killed. Tsunami events are a natural part of the Earth's geophysical system. There have been numerous events in the past and they will continue to be a threat to humanity; even more so today, when the coastal zone is occupied by so much more human activity and many more people. Therefore, tsunamis pose a very serious threat to humanity. The only way for us to face this threat is by increased knowledge so that we can meet future events by efficient warning systems and aid organizations. This book offers extensive and new information on tsunamis; their origin, history, effects, monitoring, hazards assessment and proposed handling with respect to precaution. Only through knowledge do we know how to behave in a wise manner. This book should be a well of tsunami knowledge for a long time, we hope.

\title{
How to reference
}

In order to correctly reference this scholarly work, feel free to copy and paste the following:

Marcello Di Risio, Paolo De Girolamo and Gian Mario Beltrami (2011). Forecasting Landslide Generated Tsunamis: a Review, The Tsunami Threat - Research and Technology, Nils-Axel MÃ $\llbracket r n e r(E d),. ~ I S B N: ~ 978-$ 953-307-552-5, InTech, Available from: http://www.intechopen.com/books/the-tsunami-threat-research-andtechnology/forecasting-landslide-generated-tsunamis-a-review

\section{INTECH}

open science | open minds

\section{InTech Europe}

University Campus STeP Ri

Slavka Krautzeka 83/A

51000 Rijeka, Croatia

Phone: +385 (51) 770447

Fax: +385 (51) 686166

www.intechopen.com

\section{InTech China}

Unit 405, Office Block, Hotel Equatorial Shanghai

No.65, Yan An Road (West), Shanghai, 200040, China

中国上海市延安西路65号上海国际贵都大饭店办公楼405单元

Phone: +86-21-62489820

Fax: +86-21-62489821 
(C) 2011 The Author(s). Licensee IntechOpen. This chapter is distributed under the terms of the Creative Commons Attribution-NonCommercialShareAlike-3.0 License, which permits use, distribution and reproduction for non-commercial purposes, provided the original is properly cited and derivative works building on this content are distributed under the same license. 